\title{
On the complementariness of infrasound and seismic sensors for monitoring snow avalanches
}

\author{
A. Kogelnig ${ }^{1}$, E. Suriñach ${ }^{2}$, I. Vilajosana ${ }^{3}$, J. Hübl ${ }^{1}$, B. Sovilla ${ }^{4}$, M. Hiller ${ }^{4}$, and F. Dufour ${ }^{4}$ \\ ${ }^{1}$ Institute of Mountain Risk Engineering, University of Natural Resources and Life Sciences, Vienna, Austria \\ ${ }^{2}$ Grup d'Allaus (RISKNAT), Dept. Geodinàmica i Geofísica, Fac. de Geologia, Universitat de Barcelona, Spain \\ ${ }^{3}$ Worldsensing, Clos de Sant Francesc 21, 08034, Barcelona, Spain \\ ${ }^{4}$ WSL, Swiss Federal Institute for Snow and Avalanche Research SLF, Davos Dorf, Switzerland
}

Received: 22 March 2011 - Revised: 19 July 2011 - Accepted: 22 July 2011 - Published: 26 August 2011

\begin{abstract}
The paper analyses and compares infrasonic and seismic data from snow avalanches monitored at the Vallée de la Sionne test site in Switzerland from 2009 to 2010. Using a combination of seismic and infrasound sensors, it is possible not only to detect a snow avalanche but also to distinguish between the different flow regimes and to analyse duration, average speed (for sections of the avalanche path) and avalanche size. Different sensitiveness of the seismic and infrasound sensors to the avalanche regimes is shown. Furthermore, the high amplitudes observed in the infrasound signal for one avalanche were modelled assuming that the suspension layer of the avalanche acts as a moving turbulent sound source. Our results show reproducibility for similar avalanches on the same avalanche path.
\end{abstract}

\section{Introduction}

A number of studies have shown that snow avalanches generate seismic (e.g., Saint-Lawrence and Williams, 1976; Salway, 1978; Firstov et al., 1992; Sabot et al., 1998; Suriñach et al., 2000) and infrasonic signals in the low frequency spectrum (Bedard, 1989; Firstov et al., 1992; Scott et al., 2004). Seismic signals of snow avalanches have been studied since the 1970s, focusing on monitoring (Saint-Lawrence and Williams, 1976; Salway, 1978; Suriñach et al., 2000) and warning systems (Leprettre et al., 1998; Bessason et al., 2007), investigation of their time and frequency evolution (Sabot et al., 1998; Suriñach et al., 2000, 2001; Biescas et al., 2003), and on the determination of avalanche speed

Correspondence to: A. Kogelnig (arnold.kogelnig@boku.ac.at) and seismic energy estimation (Vilajosana et al., 2007a,b). Suriñach et al. $(2000,2001)$ studied the seismic signals produced by avalanches and found different signal behaviour for distinct types of avalanches. Research on the infrasound generated by snow avalanches has increased in the last two decades (e.g., Bedard, 1989; Adam et al., 1997; Comey and Mendenhall, 2004; Scott et al., 2007) with a focus mainly on detection purposes.

Firstov et al. (1992) were one of the first researchers to study the acoustic and seismic emissions generated by snow avalanches. These authors concluded that the seismic signals recorded were generated mainly by the dense flow part of the avalanche, whereas the acoustic signals were generated principally by the turbulent snow-air flow (powder cloud). Recent studies using infrasound and seismic sensors for monitoring snow avalanches and debris flows (Suriñach et al., 2009; Kogelnig et al., 2011) have shown that infrasound and seismic signals can be correlated with each other and also with data from other measurements (e.g. flow depth for debris flows). However, an in-depth, study combining the infrasound and seismic wave fields generated by snow avalanches has not been carried out to date.

The aim of this study is to evaluate the potential of the combination of infrasound and seismic sensors for monitoring snow avalanches. We present an analysis of seismic and infrasound signals generated by four snow avalanches monitored at the Swiss Vallée de la Sionne (VDLS) test site (Sovilla et al., 2008b; Kern et al., 2009; Barbolini and Issler, 2006). Mixed avalanches that often generate a well developed powder-snow part are typical for the site. Note that these avalanches rarely flow in a pure wet- or dry-flow regime. In most cases both regimes are present. Typically, a plug flow core may be surrounded by diluted flow, particularly if the avalanche is released from altitudes where the

Published by Copernicus Publications on behalf of the European Geosciences Union. 


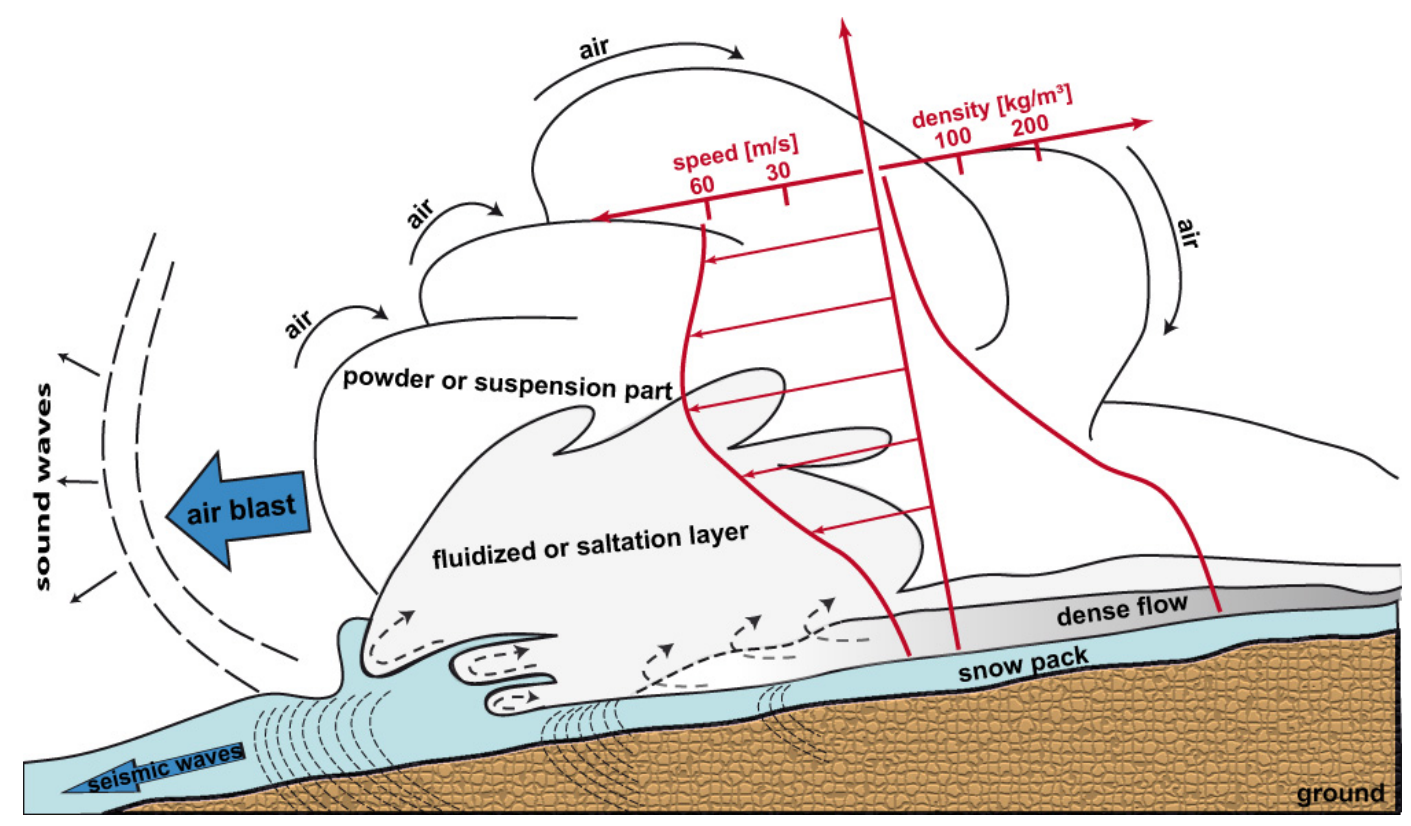

Fig. 1. Cross section of a mixed avalanche, indicating the different parts (modified after McClung and Schaerer, 2006 and Gauer et al., 2008). The sources of seismic and acoustic emissions are also indicated.

snow is still dry. Thereafter, the snow in the path becomes wet at lower altitudes (Sovilla et al., 2010a).

Mixed avalanches can be described as a three-layered structure (Fig. 1). Impact pressure measurements in VDLS show that the layer at the avalanche bottom is frequently dense and characterized by a continuous flow medium (Sovilla et al., 2008a). As we move higher up into the avalanche core, avalanche speed increases and particles at the surface of the dense flow are lifted due to the shear stress produced by the interaction with the air forming a saltation layer. Stresses are primarily transmitted by particle collisions and particle inertia. If the snow is dry and the avalanche speed is sufficiently high, a snow cloud of low density, the suspension layer, covers the exterior of the avalanche core (McClung and Schaerer, 2006). Small particles are suspended by turbulent eddies of air generated by the friction of the flowing snow interacting with the ambient air. This suspension layer behaves like a turbulent flow of a Newtonian fluid (Gauer et al., 2008).

In the following sections, we present a description of the Vallée de La Sionne test site together with an overview of the measurement setup and the data analysing methods. Section 3 is devoted to the analysis of the measurements of four avalanches of different types and sizes released naturally at the VDLS during the winter seasons $08 / 09$ to $10 / 11$. We refer to these avalanches as avalanches 1 to 4 . Their SLF archive numbers are listed in brackets to allow cross-reference with other publications. The sources of the infrasound and seismic signals generated by the snow avalanches are discussed in Sect. 4, and Sect. 5 contains the conclusions of this study.

\section{Test site, instrumentation and data treatment}

\subsection{Test site and instrumentation}

The Vallée de La Sionne (VDLS) avalanche dynamic test site is located in central Valais (Switzerland) above the city of Sion and is operated by the WSL Swiss Federal Institute for Snow and Avalanche Research, SLF (Fig. 2). The different release areas cover about 30 ha with a slope varying between $32^{\circ}$ to $45^{\circ}$. They are exposed to westerly and north-westerly winds.

At the site, avalanche dynamic measurements are routinely performed. In the runout zone, located at $1600 \mathrm{~m}$ a.s.l., a $20 \mathrm{~m}$ high pylon is instrumented with speed, pressure and flow-height sensors. Velocity, pressure and flow depth measurements performed at the pylon are used in this paper to facilitate the interpretation of the seismic and acoustic measurements. A detailed explanation of the velocity and pressure measurements is given in Kern et al. (2009) and Sovilla et al. (2008b), respectively. In a shelter opposite the avalanche slope, a pulsed Doppler radar (PDR) operated by the Federal Research and Training Centre for Forests, Natural Hazards and Landscape (BFW) measures avalanche velocities. The PDR data were used to obtain the speed profile of Avalanche 1. A detailed explanation of the radar system is given in Rammer et al. (2007). The measurement system is started automatically by seismic triggering whenever natural avalanches are released within the avalanche path.

The site has been equipped for several years with instruments to analyse the seismic signals generated by avalanches (Sabot et al., 1998; Suriñach, 2004). Infrasound (IS) sensors 
Table 1. Overview of the setup of the seismometers and infrasound (IS) sensors used in this study. The position of caverns and shelter is shown in Fig. 2.

\begin{tabular}{|c|c|c|c|c|c|}
\hline & \multirow{2}{*}{$\begin{array}{l}\text { Cavern A } \\
\text { SEISMOMETER } \\
\text { Syscom MR } 2002 \\
1 \mathrm{~Hz} \text { nat. freq. } \\
\text { Sensit. } 277 \mathrm{~V} / \mathrm{m} \mathrm{s}^{-1}\end{array}$} & \multirow{2}{*}{$\begin{array}{l}\text { Cavern B } \\
\text { SEISMOMETER } \\
\text { Mark L4-3D } \\
1 \mathrm{~Hz} \text { nat. freq. } \\
\text { Sensit. } 277 \mathrm{~V} / \mathrm{m} \mathrm{s}^{-1}\end{array}$} & \multirow[t]{2}{*}{ Cavern $\mathrm{C}$} & \multicolumn{2}{|c|}{ Shelter } \\
\hline $\begin{array}{l}\text { Aval } 1 \\
09 / 10\end{array}$ & & & & $\begin{array}{l}\text { SEISMOMETER } \\
\text { Mark L4-3D } \\
1 \mathrm{~Hz} \text { nat. freq. } \\
\text { Sensit. } 277 \mathrm{~V} / \mathrm{m} \mathrm{s}^{-1}\end{array}$ & $\begin{array}{l}\text { IS-SENSOR } \\
\text { Chaparral Model } 24 \\
0.1 \mathrm{~Hz} \text { nat. freq. } \\
\text { Sensit. } 2 \mathrm{~V} \mathrm{~Pa}^{-1}\end{array}$ \\
\hline $\begin{array}{l}\text { Aval } 2 \\
09 / 10\end{array}$ & & $\begin{array}{l}\text { SEISMOMETER } \\
\text { Mark L4-3D } \\
1 \mathrm{~Hz} \text { nat. freq. } \\
\text { Sensit. } 277 \mathrm{~V} / \mathrm{m} \mathrm{s}^{-1}\end{array}$ & & $\begin{array}{l}\text { SEISMOMETER } \\
\text { Mark L4-3D } \\
1 \mathrm{~Hz} \text { nat. freq. } \\
\text { Sensit. } 277 \mathrm{~V} / \mathrm{m} \mathrm{s}^{-1}\end{array}$ & $\begin{array}{l}\text { IS-SENSOR } \\
\text { Chaparral Model } 24 \\
0.1 \mathrm{~Hz} \text { nat. freq. } \\
\text { Sensit. } 2 \mathrm{~V} \mathrm{~Pa}^{-1}\end{array}$ \\
\hline $\begin{array}{l}\text { Aval } 3 \\
08 / 09\end{array}$ & & & $\begin{array}{l}\text { SEISMOMETER } \\
\text { Mark L4-3D } \\
1 \mathrm{~Hz} \text { nat. freq. } \\
\text { Sensit. } 277 \mathrm{~V} / \mathrm{m} \mathrm{s}^{-1}\end{array}$ & $\begin{array}{l}\text { SEISMOMETER } \\
\text { Mark L4-3D } \\
1 \mathrm{~Hz} \text { nat. freq. } \\
\text { Sensit. } 277 \mathrm{~V} / \mathrm{m} \mathrm{s}^{-1}\end{array}$ & $\begin{array}{l}\text { IS-SENSOR } \\
\text { Gefell WME } 960 \mathrm{H} \\
0.5 \mathrm{~Hz} \text { nat. freq. } \\
\text { Sensit. } 50 \mathrm{mV} \mathrm{Pa}^{-1}\end{array}$ \\
\hline $\begin{array}{l}\text { Aval } 4 \\
10 / 11\end{array}$ & & $\begin{array}{l}\text { SEISMOMETER } \\
\text { Mark L4-3D } \\
1 \mathrm{~Hz} \text { nat. freq. } \\
\text { Sensit. } 277 \mathrm{~V} / \mathrm{m} \mathrm{s}^{-1}\end{array}$ & $\begin{array}{l}\text { SEISMOMETER } \\
\text { Mark L4-3D } \\
1 \mathrm{~Hz} \text { nat. freq. } \\
\text { Sensit. } 277 \mathrm{~V} / \mathrm{m} \mathrm{s}^{-1}\end{array}$ & $\begin{array}{l}\text { SEISMOMETER } \\
\text { Mark L4-3D } \\
1 \mathrm{~Hz} \text { nat. freq. } \\
\text { Sensit. } 277 \mathrm{~V} / \mathrm{m} \mathrm{s}^{-1}\end{array}$ & $\begin{array}{l}\text { IS-SENSOR } \\
\text { Chaparral Model } 24 \\
0.1 \mathrm{~Hz} \text { nat. freq. } \\
\text { Sensit. } 2 \mathrm{~V} \mathrm{~Pa}^{-1}\end{array}$ \\
\hline
\end{tabular}

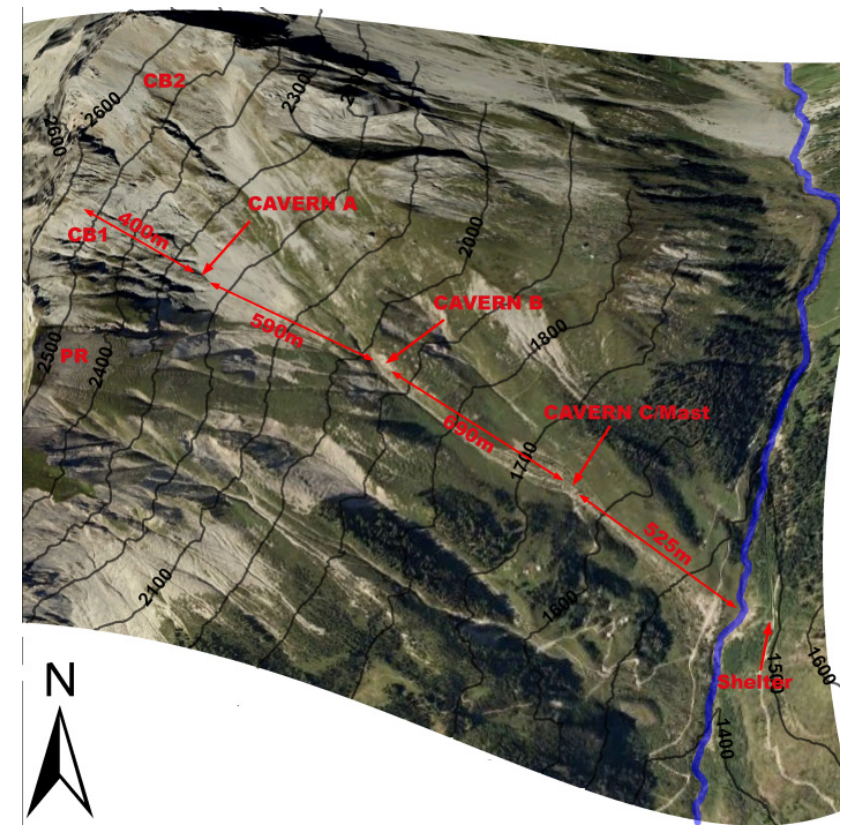

Fig. 2. Overview of the VDLS test site. Caverns A, B and C are marked. The $20 \mathrm{~m}$ instrumented pylon is located near cavern $\mathrm{C}$. PDR and the VDLS data acquisition systems are located in a shelter opposite the slope. Release areas are indicated as Pra Roua (PR), Crêta-Besse 1 (CB1) and Crêta-Besse 2 (CB2). The La Sionne river is shown in blue (source: Google Earth).

were first installed in 2008, close to the seismic sensor near the shelter. The infrasound sensors were attached to a star aligned porous garden hose setup to dampen wind noise. Figure 2 shows the location of the caverns along the avalanche path and the shelter on the counter slope where sensors are installed. The setup of the sensors and type of equipment has varied over the years (Table 1). All data were continuously recorded during all the winter seasons with a sample rate of $100 \mathrm{~Hz}$ with a Reftek DAS130 data logger and common base of time.

\subsection{Data treatment}

The methods used for data treatment in this study have been presented in previous publications (Suriñach et al., 2001, 2005; Vilajosana et al., 2007a). In line with their results, we have processed the data as following.

First, the raw signals were converted into physical parameters, velocity of the ground $\left(\mathrm{m} \mathrm{s}^{-1}\right)$ for seismic signals and air pressure $(\mathrm{Pa})$ for infrasound signals. The signals were filtered $(1 \mathrm{~Hz}$ to $40 \mathrm{~Hz})$ with a 4 th order Butterworth band-pass filter to homogenize the data. Furthermore, data were analysed using detailed time series analysis. The different wave packets in the time series allow us to determine the different sections. Total spectra using FFT (Fast Fourier Transformation) were used to analyse frequency content of these different sections. In addition, we used spectrograms for the analysis of the frequency content evolution in time because it facilitates the determination of wave time arrivals (Vilajosana et al., 2007a).

For the data interpretation we benefitted from the work of (Biescas et al., 2003), and (Suriñach et al., 2005), that associated an increase in the amplitudes in the time series with the avalanche approaching the sensor. This is also reflected 


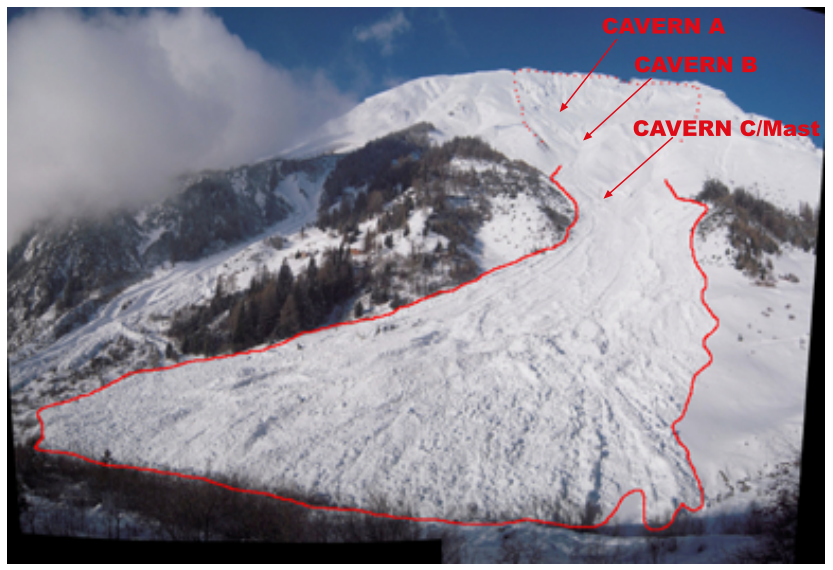

Fig. 3. Avalanche 1 occurred on 30 December 2009 at 13:30. The avalanche path and deposition zone is indicated (solid red line). View is from the shelter. The photo was taken a few days later (photo source: F. Dufour).

in an increase of the presence of higher frequencies in time giving a triangular shape in the spectrograms. These features are due to the wave attenuation phenomenon (Stein and Wylesession, 2003; Suriñach et al., 2005). Seismic waves are attenuated due to geometrical spreading and anelastic attenuation in the ground. These effects are strongly dependent on the distance between source and receiver. In contrast to seismic signals, attenuation of infrasound signals at local distances (until $5 \mathrm{~km}$ ) is negligible (Kogelnig et al., 2011, and references therein).

\section{Seismic and infrasonic data}

\subsection{Avalanche 1 (SLF \#20100003)}

\subsubsection{Avalanche description}

Avalanche 1 released naturally on 30 December 2009 at 13:30. Owing to bad visibility during and after the release, it was not possible to establish the exact position and extension of the release area. Photographs taken after the event showing part of the avalanche path and deposition extent, support the idea that the avalanche descended both right and left channels, and thus presumably released from Crêta-Besse 1 and at least part of Crêta-Besse 2 (Figs. 2 and 3). The avalanche triggered the automatic data recording system located in cavern A, reached the instrumented pylon where internal velocities, flow depths and impact pressures were measured (Fig. 4), and stopped in the river bed in the valley bottom. The PDR situated in the shelter, which was switched on by the automatic detection system located in cavern A, recorded the overall avalanche velocity from this cavern to the end of the path (Fig. 5). The avalanche was detected by

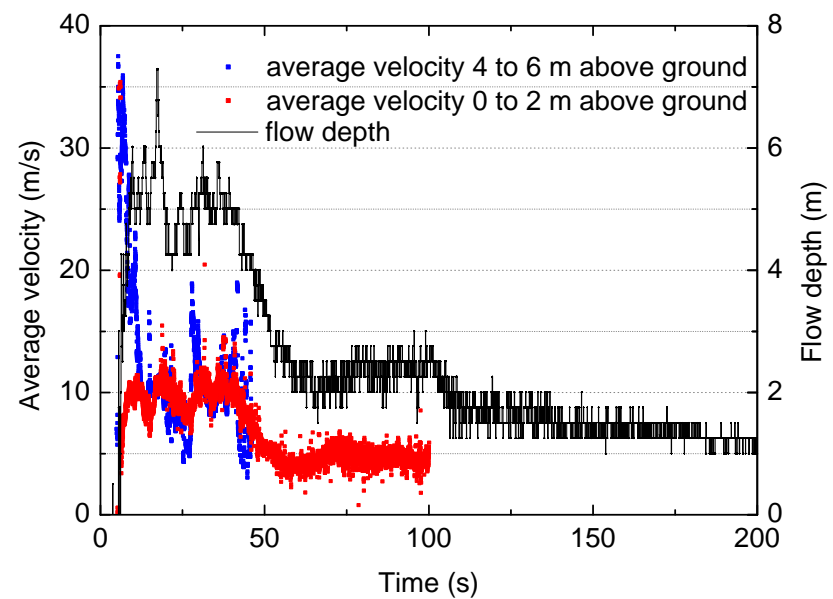

Fig. 4. Flow depth and average velocities measured at the pylon, close to cavern $\mathrm{C}$. The avalanche was characterized by a fast diluted front moving at $35 \mathrm{~m} \mathrm{~s}^{-1}$ (blue dots) and a slow large dense core moving at about $10 \mathrm{~m} \mathrm{~s}^{-1}$ (red dots). Undulations in velocity and flow depth indicate that the flow was characterized by successive surges. This large avalanche had maximum flow depths up to $6 \mathrm{~m}$ to $7 \mathrm{~m}$ at the pylon.

the sensors placed in caverns $\mathrm{A}, \mathrm{B}$ and in the shelter (Table 1).

At the time of release, the weather station Donin du Jour $(2390 \mathrm{~m})$ reported ca. $0.20 \mathrm{~m}$ of new snow in the preceding $24 \mathrm{~h}$ on a snow cover of $1.80 \mathrm{~m}$, a snow temperature of $5^{\circ} \mathrm{C}$ at a snow height of $1.0 \mathrm{~m}$ and an air temperature of $-1.5^{\circ} \mathrm{C}$. Air temperature in the release zone was $-4^{\circ} \mathrm{C}$ according to the weather station at Crêta-Besse $(2696 \mathrm{~m})$. This would indicate that, at a lower altitude, close to the deposition zone, the snow precipitation could have evolved into rain. According to measurements performed at the pylon, in the runout zone the avalanche was characterized by two main flow regimes (Fig. 4). The avalanche had a short, diluted front moving at about $35 \mathrm{~m} \mathrm{~s}^{-1}$ preceding a very large wet-dense flow, characterized by maximum flow depth in the order of $6 \mathrm{~m}$ to $7 \mathrm{~m}$, and velocity in the order of $10 \mathrm{~m} \mathrm{~s}^{-1}$. Previous studies showed that the coexistence of the two regimes indicates that the avalanche had a large powder component in the first part of the path but had evolved into a high-density flow as the avalanche entrained wet snow at lower altitudes (Sovilla et al., 2008a). The dense flow was characterized by surges recognizable in Fig. 4 as variations of flow depth and velocity.

Punctual measurements at the pylon are in agreement with the PDR measurements performed from the shelter. The avalanche reached maximum velocities of up to $55 \mathrm{~m} \mathrm{~s}^{-1}$ in the area of cavern $\mathrm{B}$, indicating the presence of a powder component. At the start of the runout zone, it decelerated suddenly to velocities typical of a slow dense flow. In the absence of PDR data in the area around cavern A, given the configuration of the triggering system, we assume that the 
avalanche, in this part of the path, had a constant acceleration and thus, the velocity grew linearly in time as shown in Fig. 5. Note that this figure reports only the values for the avalanche front velocity. However, a detailed inspection of the PDR measurements of the entire avalanche path shows that this avalanche had a large turbulent component, which lasted for more than $50 \mathrm{~s}$ (Rammer, personal communication).

The deposition morphology was characterized by the typical patterns of a large wet-dense flow. The presence of numerous levees and complex structures suggests that the deposition was probably built up in several stages (Fig. 3). The earlier deposits were successively overrun by subsequent parts of the flow, as has been evidenced in other avalanches at this site (Sovilla et al., 2010b). In a first approximation, we estimate the avalanche to have a classification size of 5 (mass of the order of $10^{5} \mathrm{t}$ and path length $2000 \mathrm{~m}$, Canadian snow avalanche size classification, McClung and Schaerer, 1980).

\subsubsection{Seismic and infrasonic data description}

Figure 6 shows the seismic (N-S component) and infrasound signals measured during the avalanche. In the time interval $[500 \mathrm{~s}$ to $620 \mathrm{~s}$, the seismic signals of caverns $A$ and B present numerous energy peaks $\left(10^{-3} \mathrm{~m} \mathrm{~s}^{-1}\right)$, which are related to impacts produced by the avalanche flowing over the caverns (Fig. 6a and b). A detailed inspection of this time interval allowed us to determine the time at which the avalanche reached caverns A and B $(534 \mathrm{~s}$ and $548 \mathrm{~s}$, respectively) (Fig. 6a and b). Accordingly, the avalanche front covered the distance between caverns A and B, $590 \mathrm{~m}$, in $14 \mathrm{~s}$, yielding an average speed of the avalanche front of approximately $42 \mathrm{~m} \mathrm{~s}^{-1}$. This value is consistent with the value obtained from the PDR, which shows velocities between $45 \mathrm{~m} \mathrm{~s}^{-1}$ to $48 \mathrm{~m} \mathrm{~s}^{-1}$ for this section (Fig. 5) and is also consistent with the maximum punctual velocity measured at the pylon, of $35 \mathrm{~m} \mathrm{~s}^{-1}$ (Fig. 4).

The average amplitudes recorded in cavern $\mathrm{B}$ are higher than those recorded in cavern A. The amplitudes of the seismic signals obtained in the shelter over the same time interval [500 s to $620 \mathrm{~s}$ ] (Fig. 6d) are two orders of magnitude smaller and have a different shape (Fig. 6f). At the shelter, the amplitudes increase with time, yielding a maximum at a later interval [ $630 \mathrm{~s}$ to $740 \mathrm{~s}]$. The increase in amplitudes in a triangular shape (Fig. 6d) indicates that the avalanche approached the sensor in the shelter. Interestingly, infrasound sensors near the shelter detected the avalanche $25 \mathrm{~s}$ before it reached the cavern A (Fig. 6a). In the time interval [500 s to $620 \mathrm{~s}]$, high amplitudes up to $5 \mathrm{~Pa}$ with a spindle shape were detected in the infrasound sensor (Fig. 6c). In this time interval, the avalanche flowed over caverns A and B and the signal amplitudes were the smallest in the seismic sensor near the shelter.

To interpret the infrasound signals in the time window [500 s to $620 \mathrm{~s}$ ], we compared the time series from the

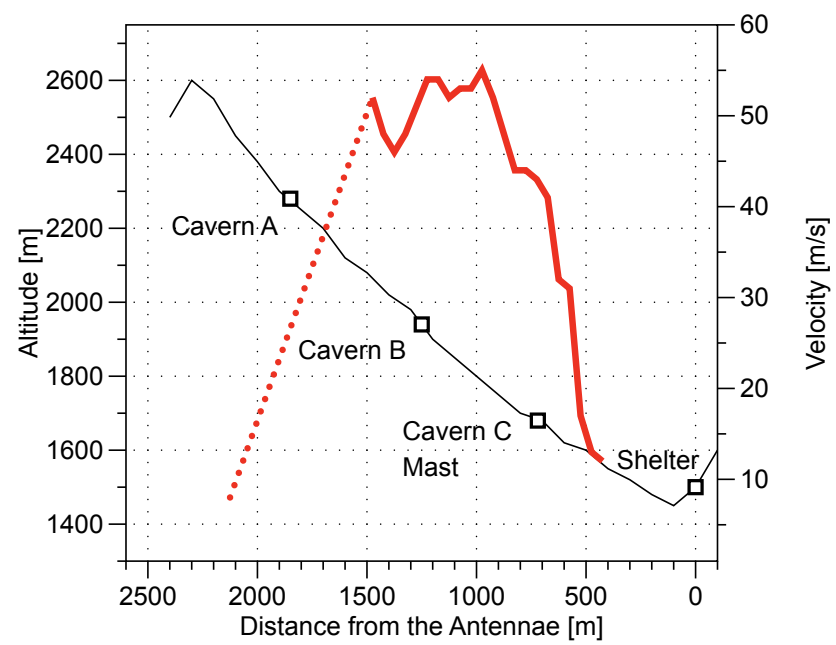

Fig. 5. Avalanche front velocity measured with the PDR for Avalanche 1 (solid red line). Velocity was assumed to grow linearly in time (dotted red line) above Cavern B in the absence of data.

infrasound and the seismic sensor located near the shelter (Fig. 6e and f, respectively). Figure 7 presents the total spectra of the seismic and infrasound signals. The maximum energy is centred at $1 \mathrm{~Hz}$ to $3 \mathrm{~Hz}$ in the infrasound signal, whereas it is shifted to $6 \mathrm{~Hz}$ to $8 \mathrm{~Hz}$ in the seismic signal. However, seismic data also have energy in the range of $1 \mathrm{~Hz}$ to $3 \mathrm{~Hz}$ as indicated in Fig. 7c. After filtering the seismic signal between $1 \mathrm{~Hz}$ to $3 \mathrm{~Hz}$, the time series shows in this interval a spindle shape, similar to that of the infrasound signal, with maximum amplitudes of the order of $3 \times 10^{-7} \mathrm{~m} \mathrm{~s}^{-1}$ (Fig. 6g).

At approx. $600 \mathrm{~s}$, the amplitudes in the infrasound start to decrease and a value of ca. $1 \mathrm{~Pa}$ is maintained thereafter (arrows in Fig. 6c). By contrast, the amplitudes of the seismic signals in the shelter start to increase up to $1 \times 10^{-4} \mathrm{~m} \mathrm{~s}^{-1}$ (Fig. 6d). Arrows in Fig. 6d mark two different surges of the avalanche in agreement with the measurements at the pylon (Fig. 4). Seismic peaks at the end of the surges characterize the deposition processes as observed in earlier seismic studies (e.g., Suriñach et al., 2000). The two surges can also be identified in the infrasonic data with the same length and arrival time, but with lower amplitudes. The total duration of the avalanche based on the seismic and infrasonic data was approximately $500 \mathrm{~s}$ [ $500 \mathrm{~s}$ to $1000 \mathrm{~s}$ ] (Fig. 6).

\subsection{Avalanche 2 (SLF \#20100003b)}

\subsubsection{Avalanche description}

On 30 December 2010, about $5 \mathrm{~min}$ before Avalanche 1, we detected an avalanche which was released in the area known as Pra Roua, situated immediately on the left of CrêtaBesse 1 (Fig. 2). The avalanche path is located to the south of caverns A and B and it is characterized by two narrow 

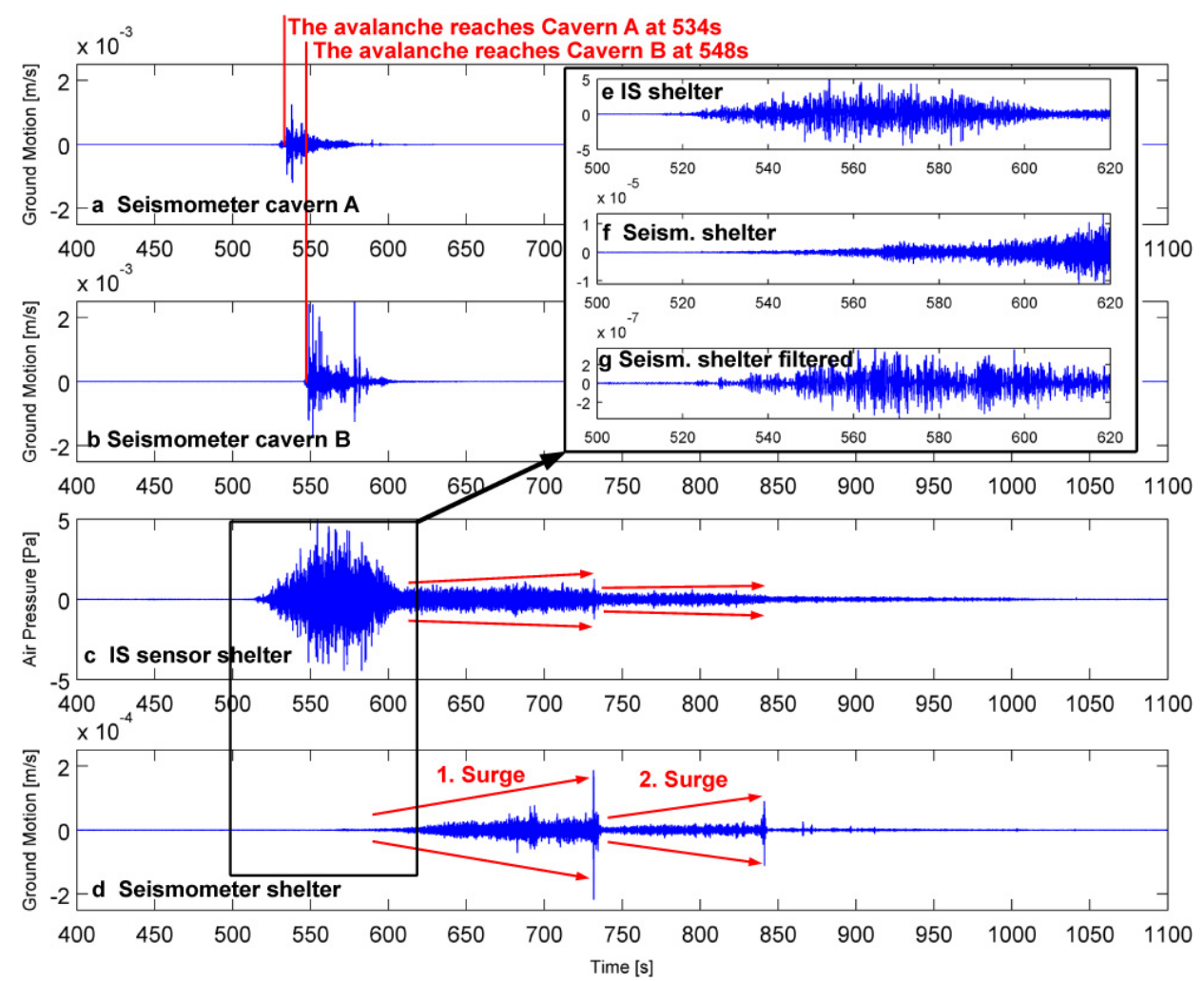

Fig. 6. Seismic (N-S component) and infrasonic data from Avalanche 1. Signals are represented with a common base of time. (a) Seismogram in cavern A; (b) Seismogram in cavern B; (c) infrasound time series near the shelter; (d) Seismogram near the shelter; (e) magnified infrasound time series; (f) magnified Seismogram near the shelter; and (g) magnified filtered (1-3 Hz) Seismogram near the shelter. Red arrows indicate the infrasound signal associated with the different surges of the avalanche. Note the similar spindle shape between the seismic (g) and infrasound signals (e). Magnified time series are shown with a different scale of amplitude and all series are plotted on an arbitrary time scale.

channels which join in a common deposition zone ca. $200 \mathrm{~m}$ southeast of the deposition area of Avalanche 1 (Fig. 8). Avalanches that release from Pra Roua, may also enter the gully where the seismic sensors and instrumented pylon are located. However, in this case, the avalanche did not trigger the automatic data recording system and did not reach the instrumented pylon. Weather and snowcover characteristics are similar to those of Avalanche 1. No dynamical data are available for this event. The avalanche was detected in the sensors placed in cavern B and in the shelter (Table 1). In the deposition zone, the avalanche self-formed a channel delimited by bounding levees and it flowed down to the river. Given the dimensions of the deposition zone shown in Fig. 8, the classification size of the avalanche was approx. 4 (mass $10^{4} \mathrm{t}$, path length $2000 \mathrm{~m}$ ).

\subsubsection{Seismic and infrasonic data description}

Figure 9 shows the time series of the seismic (N-S component) and infrasound signals. The total duration of the avalanche signals was approx. $230 \mathrm{~s}$ [180 s to $410 \mathrm{~s}]$. The time series show two-wave packages of approx. $25 \mathrm{~s}$ to $30 \mathrm{~s}$ in the interval [ $200 \mathrm{~s}$ to $260 \mathrm{~s}$ ] in all three sensors. Each wave packet has a spindle shape with high amplitudes and a similar shape (Fig. 9, curved lines). Note that the seismic signals obtained in cavern B show a shape that is markedly different from that of those obtained in Avalanche 1 because of the different paths of the avalanches.

In the interval [ $190 \mathrm{~s}$ to $260 \mathrm{~s}$ ], the averaged amplitudes of the seismic signals in cavern B were slightly higher than those recorded in the shelter (all of the order of $10^{-6} \mathrm{~m} \mathrm{~s}^{-1}$ ). The seismic amplitudes decreased rapidly at $260 \mathrm{~s}$ and remained almost constant $\left(2 \times 10^{-7} \mathrm{~m} \mathrm{~s}^{-1}\right)$ between $260 \mathrm{~s}$ and $400 \mathrm{~s}$, although peaks associated with the deposition phase were visible in the interval $300 \mathrm{~s}$ to $400 \mathrm{~s}$ (Fig. 9a, c, arrows). During this interval the amplitudes in the shelter were generally slightly higher than those in cavern B.

The maximum amplitudes of the infrasound signal were $1 \mathrm{~Pa}$ (average values $0.5 \mathrm{~Pa}$ ). The amplitudes decrease drastically after $260 \mathrm{~s}$ (Fig. 9b). A detailed inspection of the signals in the time interval [180s to $220 \mathrm{~s}$ ] (Fig. 9d-f), which corresponds to the initial phase of the avalanche, shows that energetic infrasound signals arrived at the shelter approx. $5 \mathrm{~s}$ later than the seismic signals. This delay can be explained if 

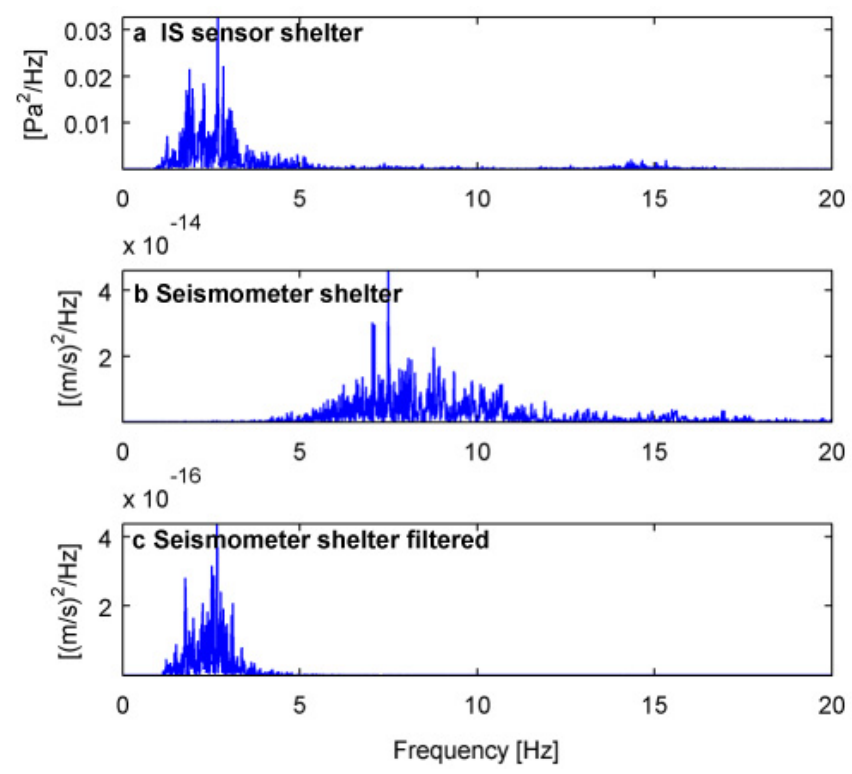

Fig. 7. Total spectra for the time interval [500s to $620 \mathrm{~s}$ ] of Avalanche 1 (Fig. 6). (a) Infrasound time signal from the sensor near the shelter; (b) N-S component Seismogram near the shelter; and (c) N-S component filtered (1-3 Hz) Seismogram near the shelter. Note the different scale of amplitudes $\left(10^{-16}\right)$.

the sources of the seismic and infrasound signals originated simultaneously. The observed delay matches the differences in the wave travel times if we consider the propagation speed of the seismic (approx. $2500 \mathrm{~m} \mathrm{~s}^{-1}$ in VDLS) and infrasound (343 $\mathrm{m} \mathrm{s}^{-1}$, at standard temperature and pressure) waves and the distances involved between source and sensors. This result indicates that the start of the avalanche generated seismic and infrasound wave fields simultaneously.

\subsection{Avalanche 3 (SLF \#20093025)}

\subsubsection{Avalanche description}

Avalanche 3 occurred naturally on 11 February 2009 at 01:30. Owing to bad visibility during and after the release, it was not possible to establish the exact position and extension of the release area. Photographs (taken after the event) of part of the avalanche path and the deposition extent suggest that the avalanche was released from Crêta-Besse 1 (Fig. 10).

The avalanche triggered the automatic data recording system in cavern A, reached the instrumented pylon where internal velocity, flow depth and impact pressure were measured, and stopped at a short distance from the pylon (Fig. 10). The records from the weather station at Donin du Jour (2390 m) reported ca. $0.40 \mathrm{~m}$ of new snow in the preceding $48 \mathrm{~h}$ on a snow cover of $2.00 \mathrm{~m}$ and a snow temperature of $-3{ }^{\circ} \mathrm{C}$ at a snow height of $1.00 \mathrm{~m}$. Air temperature in the release zone was $-14{ }^{\circ} \mathrm{C}$.
The measurements at the pylon indicate that the avalanche was characterized by a low density, diluted flow regime (Fig. 11) with a velocity up to $30 \mathrm{~m} \mathrm{~s}^{-1}$ and flow depths between 1 and $2 \mathrm{~m}$. Two main surges [ $1 \mathrm{~s}$ to $7 \mathrm{~s}, 8 \mathrm{~s}$ to $14 \mathrm{~s}$ ] are visible in Fig. 11 as variations of flow depth and velocity. The thin deposition and the difficulty of detecting precise deposition boundaries indicate that the avalanche did not have an important dense core at the site of the pylon. Given the dimensions of the deposition zone shown in Fig. 10, the classification size of the avalanche is approx. $3\left(\right.$ mass $10^{3} \mathrm{t}$, path length $1000 \mathrm{~m}$, although the path length exceeded $1000 \mathrm{~m}$ in this case). This avalanche was detected in the sensors placed in cavern $\mathrm{C}$ and the shelter (Table 1).

\subsubsection{Seismic and infrasonic data description}

Figure 12 shows the seismic ( $Z$ component) and infrasound signals. The impact of the avalanche against the pylon and the passage of the avalanche over cavern $\mathrm{C}$, situated approx. $50 \mathrm{~m}$ below the pylon are observed by the sudden increase in amplitudes (approx. $1 \times 10^{-4} \mathrm{~m} \mathrm{~s}^{-1}$ ) at $103 \mathrm{~s}$ (Fig. 12a). This is also observed in the seismic sensors near the shelter (Fig. 12c). The impact against the pylon is less noticeable in the infrasonic data (Fig. 12b). The seismic energy is detected at approx. $55 \mathrm{~s}$ in cavern $\mathrm{C}$ (Fig. 12d, red arrow), whereas it is not significant in the two sensors near the shelter at this time. The energy is detected in these sensors approx. $15 \mathrm{~s}$ later (70 s) (Fig. 12e and f, red line). The high amplitude energy disappears at approx. $120 \mathrm{~s}$ in cavern $\mathrm{C}$, whereas the seismic signal increases at this time (up to $150 \mathrm{~s}$ ) in the sensor near the shelter.

Infrasonic energy is observed in the whole interval [70 s to $150 \mathrm{~s}$ ]. The shape of the time series obtained in the infrasound and seismic sensor near the shelter is very similar. Both have a spindle shape (Fig. 12b and c) and the duration [70 s to $150 \mathrm{~s}$ ] and arrival time of the avalanche signals are similar.

\subsection{Avalanche 4 (SLF \#20103004)}

\subsubsection{Avalanche description}

During the days of 6 and 7 December 2010, three avalanches were released naturally at the Vallée de La Sione test site. On 6 December two avalanches occurred, one at 06:22 (SLF \#20103002) and the second at 18:31 (SLF \#20103003). The third avalanche (SLF \#20103004), known as Avalanche 4, occurred a few hours later on 7 December at 03:36. The avalanches were released after a snow precipitation of ca. $0.50 \mathrm{~m}$ in the preceding $48 \mathrm{~h}$ on a snow cover of $0.80 \mathrm{~m}$ and a snow temperature of $-3{ }^{\circ} \mathrm{C}$ at a snow height of $1.00 \mathrm{~m}$. Air temperature in the release zone was $-4^{\circ} \mathrm{C}$. 

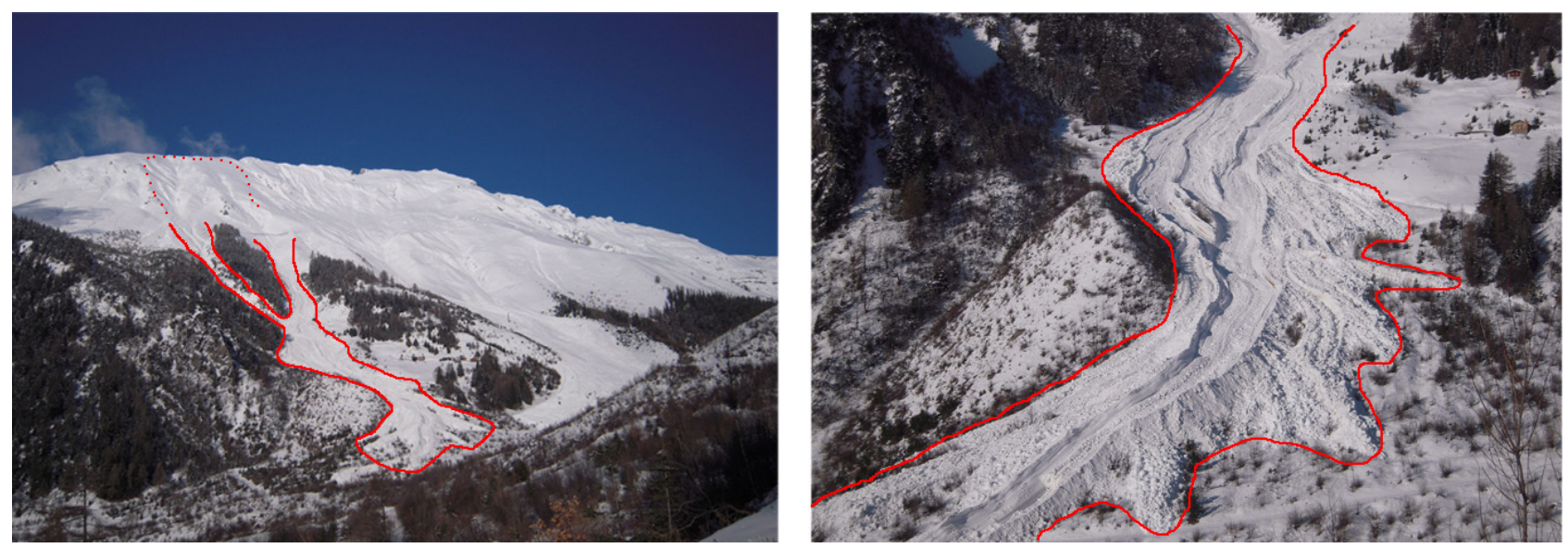

Fig. 8. Left: Avalanche 2 occurred on 30 December 2009, at 13:25 in a path close to the monitored area. The avalanche release zone is indicated. Right: detail of the avalanche deposit (photo source: SLF).

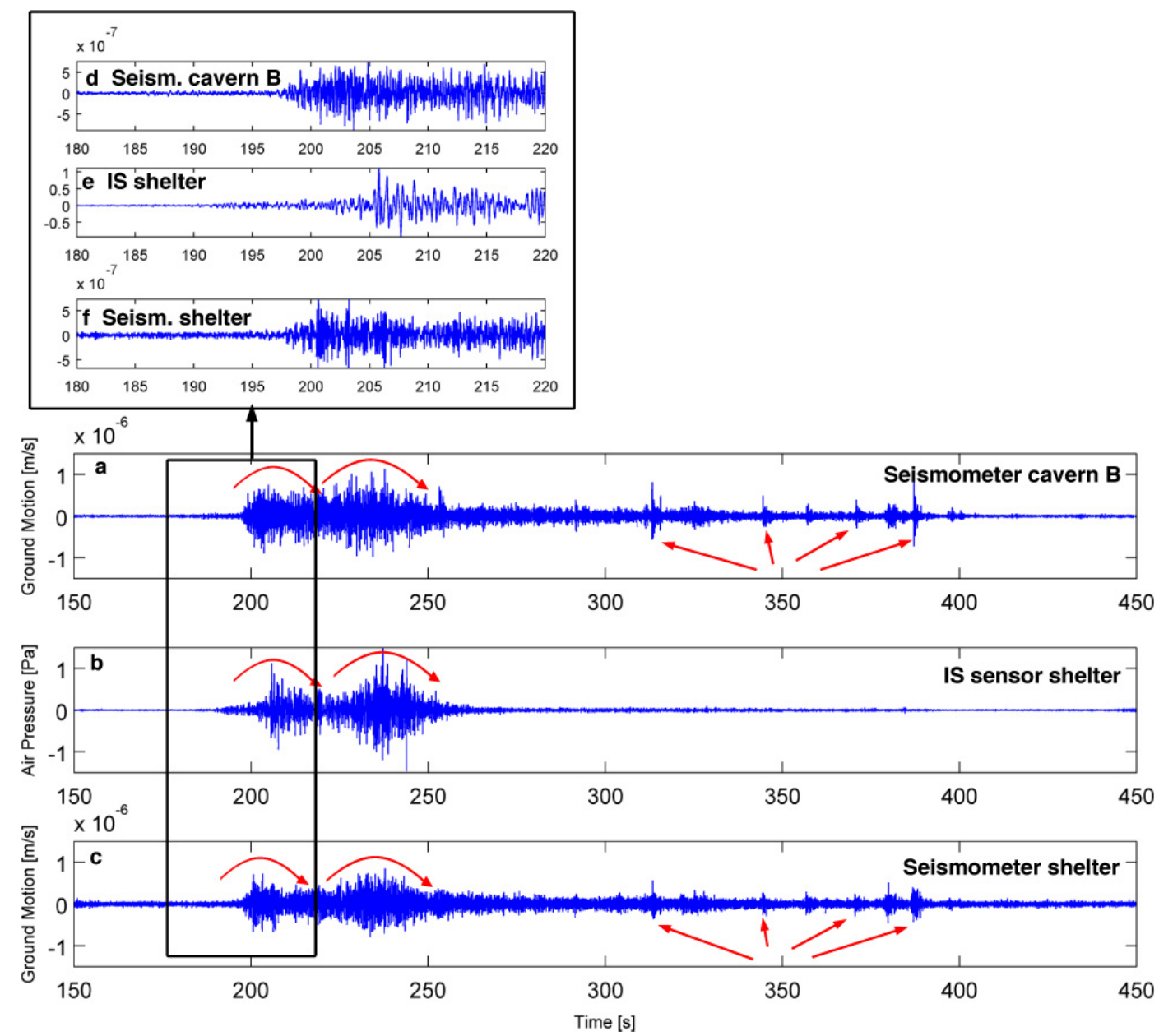

Fig. 9. Seismic (N-S component) and infrasonic data from Avalanche 2. Signals are represented with a common base of time. (a) Seismogram in caverns B; (b) infrasound time series near the shelter; (c) Seismogram near the shelter; (d) magnified Seismogram in cavern C; (e) magnified infrasound time series; and (f) magnified Seismogram near the shelter. Curved arrows indicate two different surges of the avalanche and straight arrows indicate the seismic peaks associated with the stopping phase of the avalanche. 


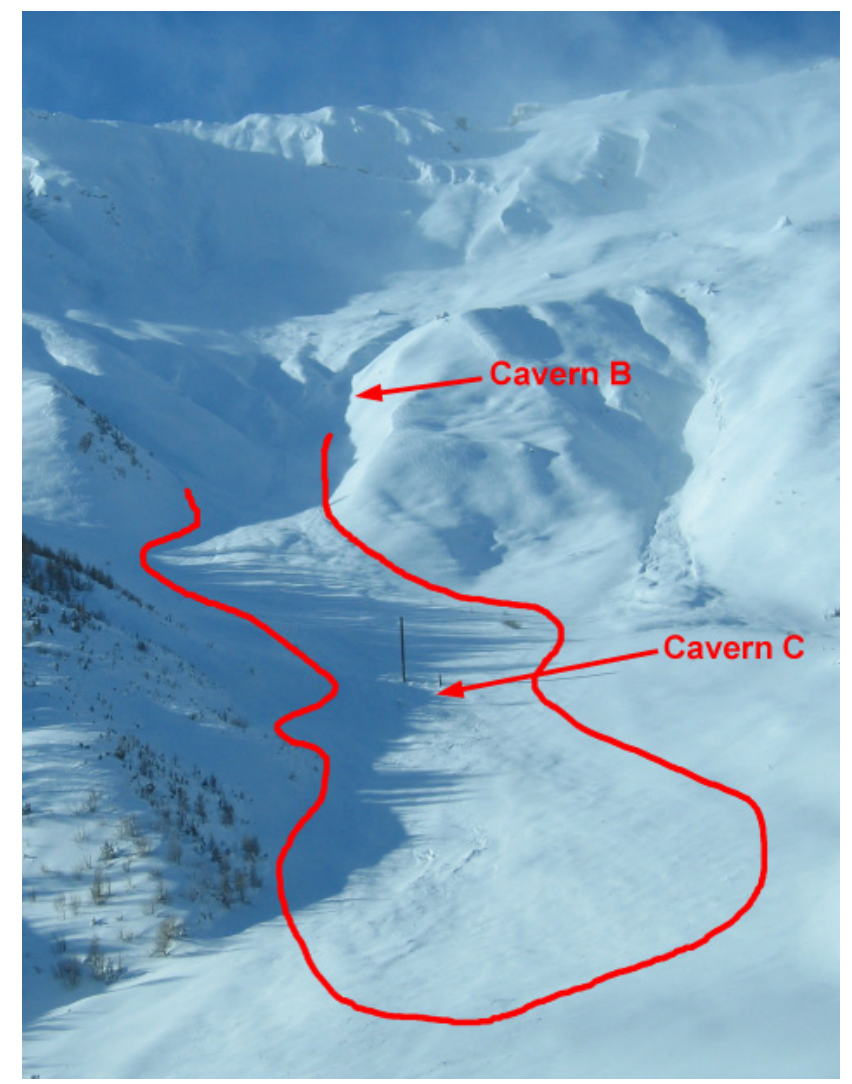

Fig. 10. Avalanche 3 viewed from the shelter. Avalanche 3 occurred on 11 February 2009 at 01:30 (photo source: F. Dufour). The avalanche deposit is outlined in red. The $20 \mathrm{~m}$ measurement pylon is visible above the red arrow indicating the location of cavern $\mathrm{C}$. Deposit boundaries are difficult to identify.

Owing to poor visibility during and after the release, it was not possible to establish the exact position and extension of the different release areas. However, a laserscanning campaign undertaken a day later indicated that the avalanches were released from Crêta-Besse 1 and from part of CrêtaBesse 2 (Sovilla et al., 2010). Automatic pictures taken each $1 / 2 \mathrm{~h}$ in the area of the pylon indicate that avalanche SLF \#20103003 followed the left couloir and was probably released from Crêta-Besse 1. Avalanche 4 descended the left couloir and was probably released from the area of CrêtaBesse 1 and part of Crêta-Besse 2. The release area and the path of the first avalanche (\#20103002) are very uncertain but we assume that it followed the left and partly the right channel. However, no clear information on the path followed by these avalanches is available at the moment. Figure 13 shows an estimate of the release boundaries and the extension of the area affected by the three avalanches. Avalanches \#20103003 and Avalanche 4 triggered the automatic recording system and hit the measurement pylon where internal velocities, flow depth and impact pressure were measured. However, no data are available for the avalanche that occurred in the morning on 6 December. Only Avalanche 4 will be analyzed in detail.

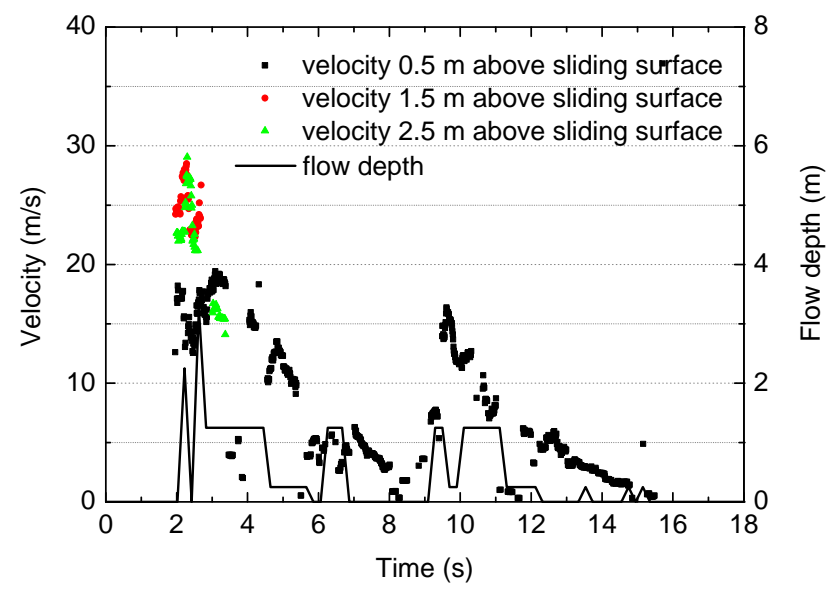

Fig. 11. Avalanche 3: flow depth and internal velocities measured at the pylon, close to cavern $\mathrm{C}$. The avalanche was characterized by a low density, diluted flow moving up to $30 \mathrm{~m} \mathrm{~s}^{-1}$ (dots). The flow depth was small. Undulations in velocity and flow depth indicate that the flow had two surges.

Figure 14 shows velocity and flow depth measured at the pylon for Avalanche 4. At the pylon, the avalanche had a slow dense flow regime characterized by a velocity of up to $5 \mathrm{~m} \mathrm{~s}^{-1}$ and flow depths in the order of $1 \mathrm{~m}$. Because this avalanche reached the valley bottom, we expect velocity in the upper part of the path to have been high enough to develop a suspension layer. The low velocity at the pylon suggests that this layer disappeared before reaching the pylon. An explanation for this behaviour is that the preceding avalanches had already entrained all the snow cover along the left channel, hindering the development of a suspension layer in Avalanche 4 in the lower avalanche path. This behaviour has been observed in other studies (Sovilla et al., 2006).

Figure 13 shows the deposits of the avalanches as pictured in the early morning of 7 December. From the analysis of pictures taken after this avalanche, we deduce that Avalanche 4 self-formed a channel delimited by levees engraved into the deposit of the previous avalanches (Fig. 13). From laserscanning measurements performed after both avalanches we estimated a total deposit volume of about $115000 \mathrm{~m}^{3}$. Assuming a density of $400 \mathrm{~kg} \mathrm{~m}^{-3}$ we can estimate that the avalanches had a total mass of about $46000 \mathrm{t}$. Thus, in first approximation, the classification size of both avalanches is approx. 4 (mass $10 \mathrm{~m}^{4} \mathrm{t}$, path length $2000 \mathrm{~m}$ ). Avalanche 4 was detected in the sensors placed in caverns B, $\mathrm{C}$ and shelter (Table 1).

\subsubsection{Seismic and infrasonic data description}

Figure 15 presents the seismic and infrasound signals recorded during Avalanche 4. A preliminary glance at the signals shows that the signal shapes are similar to those of Avalanche 1, which suggests a similar behaviour of 


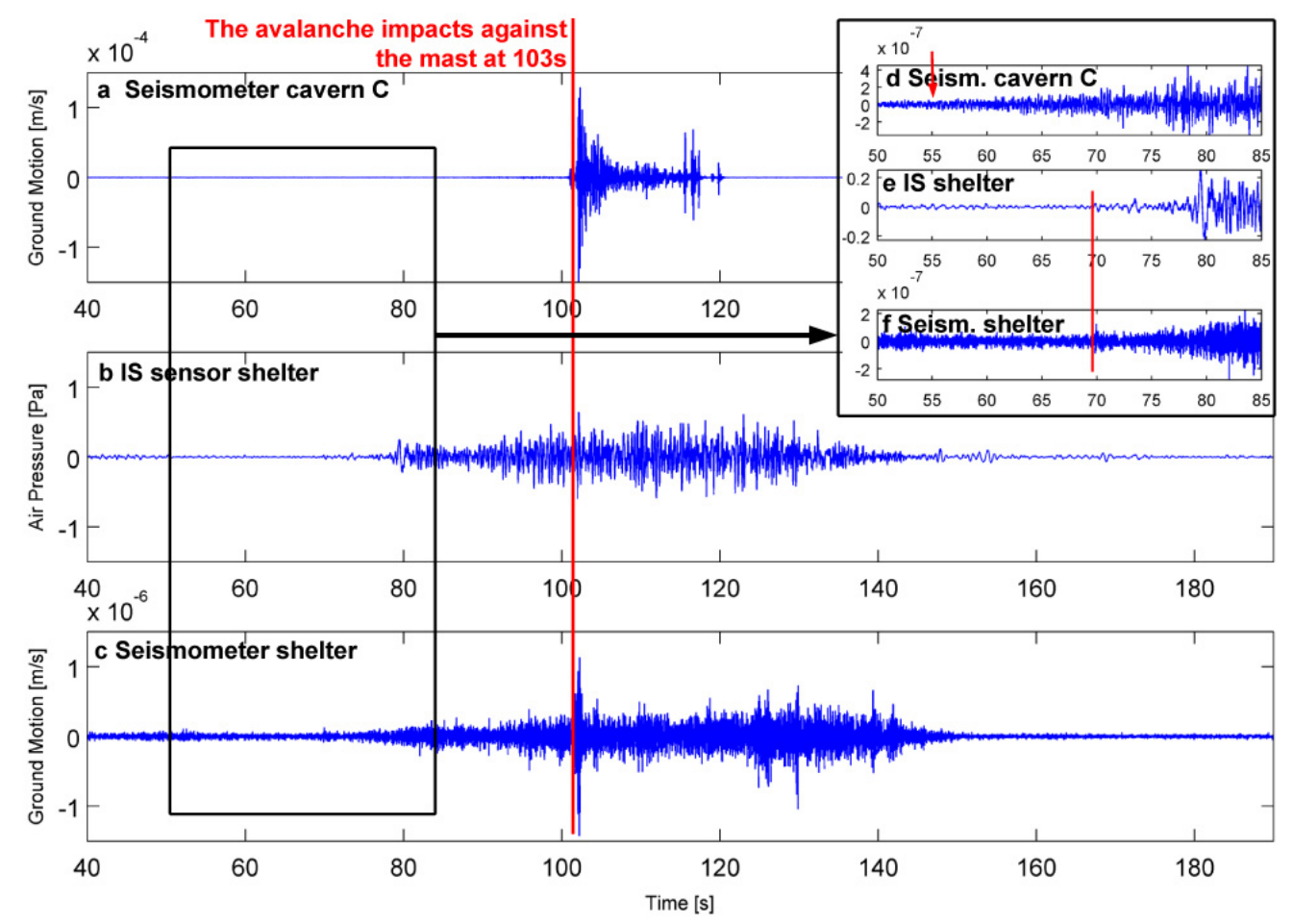

Fig. 12. Seismic $Z$ component and infrasonic data from Avalanche 3. Signals are represented with a common base of time. (a) Seismogram in cavern C; (b) infrasound time series near the shelter; (c) Seismogram near the shelter; (d) magnified Seismogram in cavern C, the arrow indicates the signal arrival (e) magnified infrasound time series; and (g) magnified Seismogram near the shelter, the red line indicates the signal arrival. Note the spindle shape of the signal in (b) and (c). Magnified time series are shown with a different scale of amplitude and all series are plotted on an arbitrary time scale.

both avalanches. The sudden increase in amplitudes, up to $10^{-4} \mathrm{~m} \mathrm{~s}^{-1}$, in the time series in cavern $\mathrm{B}$, at $103 \mathrm{~s}$, and in cavern C, at $137 \mathrm{~s}$ (Fig. 15a and b) reflects the passage of the avalanche. Figure $15 \mathrm{a}$ and $\mathrm{b}$ also show that seismic signal amplitudes decreased more slowly in cavern $\mathrm{C}$ than in cavern B.

Avalanche 4 travelled a distance of $690 \mathrm{~m}$ between caverns $B$ and $C$ with an average speed of approx. $20 \mathrm{~m} \mathrm{~s}^{-1}$. Measurements at the pylon show (Fig. 14) that Avalanche 4 reached the pylon at a velocity of about $5 \mathrm{~m} \mathrm{~s}^{-1}$. One explanation for this difference in the speed is that the avalanche decelerated in the gully. This sudden deceleration was probably due to the lack of snow to entrain in the lower part of the path after the passage of the previous avalanches. This also accounts for the slower amplitude decrease in seismic signals in cavern $\mathrm{C}$ in comparison to cavern B. At the shelter, the seismic time signal has a triangular shape, which indicates that the avalanche was approaching the sensor. The arrows in Fig. 15d indicate the increase in amplitudes of the seismic signal and the presence of peaks associated with the stopping phase of the avalanche. The signals also suggest that Avalanche 4 underwent only one surge.

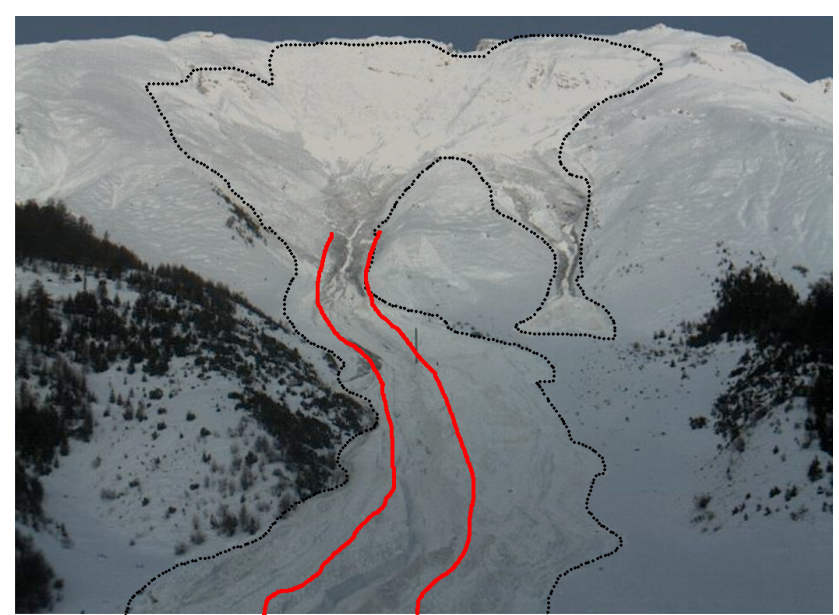

Fig. 13. Estimated boundaries of avalanches on 6 and 7 December 2010. Red line: Channel of Avalanche 4, delimited by levees. Avalanche 4 was probably released from the far left of Crêta-Besse 1 and from part of Crêta-Besse 2. The dashed black line indicates the total area affected by the avalanche activity on 6 and 7 December 2010 (photo source: SLF). 


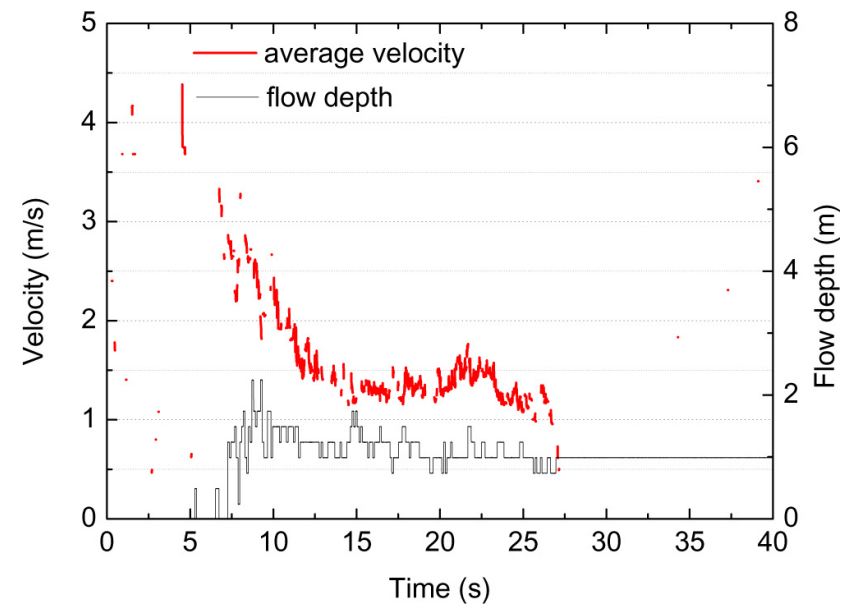

Fig. 14. Avalanche 4. Flow depth and internal velocities measured at the pylon, close to cavern $\mathrm{C}$. This avalanche was characterized at the beginning of the runout zone by a small dense flow with velocity up to $4 \mathrm{~m} \mathrm{~s}^{-1}$ to $5 \mathrm{~m} \mathrm{~s}^{-1}$ and flow depth in the order of $1 \mathrm{~m}$.

In the infrasound signal, two wave packages of different amplitudes are observed (Fig. 15c). The amplitudes in the infrasound signal rapidly decrease in the time interval [90 s to $100 \mathrm{~s}$ ] just before the avalanche reaches cavern $\mathrm{B}$. The time series of the infrasound and filtered seismic signals behave in the same manner (spindle shape) when the avalanche is in the upper avalanche path (Fig. 15e and g). Based on the seismic and infrasonic data, the total duration of the avalanche was approx. $495 \mathrm{~s}$ [ $40 \mathrm{~s}$ to $535 \mathrm{~s}$ ] (Fig. 15).

\subsection{Summary of seismic and infrasonic data}

In the previous sections, signals generated by avalanches of varying sizes at VDLS are described. Table 2 shows that the maximum amplitudes of the infrasound and seismic signals change from avalanche to avalanche.

The seismometers located in the caverns provide information about the position of the avalanche along the path and about the duration of the flow over the caverns. The maximum seismic amplitudes generated by an avalanche depends on its size, velocity, density and distance source - sensors (Suriñach et al., 2001; Biescas, 2003; Vilajosana et al., 2007b). As expected, Avalanche 1 had the largest amplitudes with a similar flow duration in both caverns (Table 2). The amplitudes in cavern B were slightly higher than those in cavern A, indicating that the avalanche speed and size were increasing. Avalanche 3 had smaller amplitudes attributable to the smaller size and a more diluted flow. Finally, for Avalanche 4 the seismic amplitudes monitored in cavern B were slightly higher than those observed in cavern $\mathrm{C}$, whereas the flow duration over cavern $\mathrm{C}$ was much longer. This can be explained by a deceleration of the avalanche before cavern $\mathrm{C}$ and a more dense flow regime in the lower avalanche path.
As the avalanches approached the seismometer in the shelter, an increase in the seismic amplitudes was produced. Again, the large dense flow of Avalanche 1 yielded higher amplitudes than the smaller diluted Avalanche 3, which stopped further away from the shelter than Avalanche 1. In the seismic data of Avalanche 3, the impact of the avalanche against the pylon can be clearly identified. This can be attributed to the fact that the avalanche had a large diluted part that impacted against the pylon, generating a significant seismic signal. This signal is well observed over the relatively smaller seismic amplitudes caused by the friction in the snow cover. In Avalanches 1 and 4, the seismic signal produced by the impact of the avalanches against the pylon was masked by the higher signal amplitudes generated by the flow of the dense part. An increase in seismic amplitudes in the shelter is also clearly observed in Avalanche 4. The maximum amplitudes attained values smaller than those of Avalanche 1, which is in accordance with the avalanche size. In contrast to Avalanche 1, the signals suggest that Avalanche 4 had only one surge. Avalanche 2, whose path was further away from the sensors, yielded smaller amplitudes in the seismic sensors placed in the shelter and in cavern B. The peaks due to the stopping phase of the avalanche are detected only in the seismic signal. Infrasound signals at the shelter are observed before the avalanche passed over the caverns in the upper avalanche path. In the lower avalanche path, the infrasound amplitudes rapidly decreased. Avalanche 1 yielded the largest infrasound amplitudes, up to $5 \mathrm{~Pa}$. According to PDR velocity measurements, in the upper part of the path, the avalanche had the highest velocities, up to $55 \mathrm{~m} \mathrm{~s}^{-1}$, and probably developed a large suspension layer. Avalanche 2 released from the Pra Roua, in similar meteorological and snow cover conditions had much smaller infrasound amplitudes, up to $1 \mathrm{~Pa}$.

The smallest infrasound signal amplitude, up to $0.6 \mathrm{~Pa}$, was recorded for Avalanche 3, probably indicating a smaller suspension layer. Again, these data are in agreement with the measurements at the pylon and with the total duration of the flow, which indicates that Avalanche 3 had the smallest volume of all the avalanches studied (Fig. 11). Finally, we recorded maximum infrasound amplitudes of $2.5 \mathrm{~Pa}$ for Avalanche 4. The average avalanche speed between cavern $\mathrm{B}$ and $\mathrm{C}$ obtained from the seismic signals was $20 \mathrm{~m} \mathrm{~s}^{-1}$. This value indicates that Avalanche 4 was able to form a suspension layer in the upper part of the path. This is also consistent with the duration of the high amplitudes in the infrasound signals that rapidly decrease before the avalanche reaches cavern B (Fig. 15c). The simultaneous decrease in the amplitudes in the infrasound signal and the increase in the amplitudes of the seismic signal is also a common characteristic for Avalanches 1 and 4, (Figs. 6c, d and 15c, d).

Interestingly, infrasound signals showed a spindle shape in all the avalanches studied. The length of this spindle wave packet is of the order of $60 \mathrm{~s}$ to $80 \mathrm{~s}$ in all cases regardless of the length of the seismic signals, which depends on the 

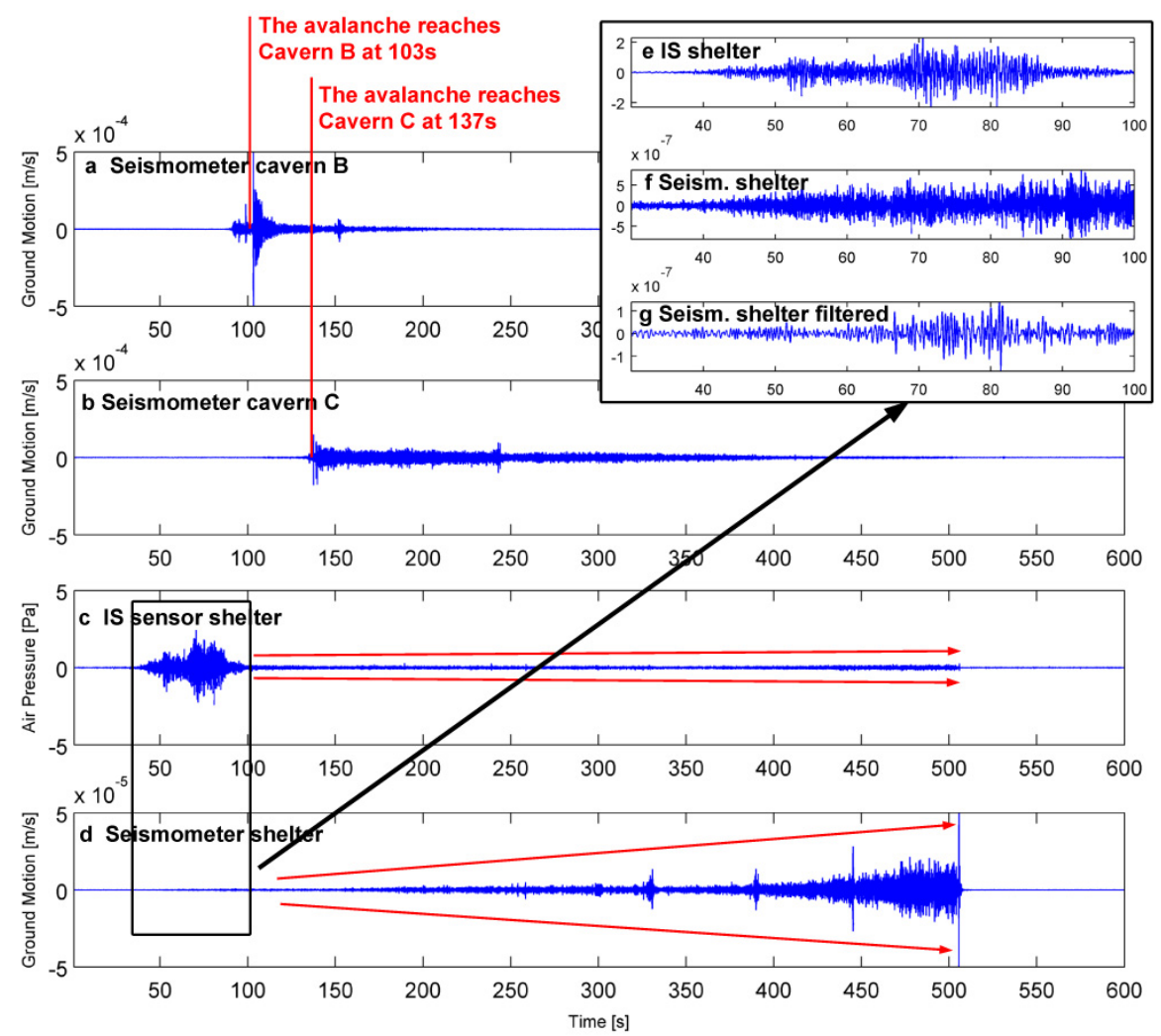

Fig. 15. Seismic (N-S component) and infrasonic data from Avalanche 4. Signals are represented with a common base of time. (a) Seismogram in cavern B; (b) Seismogram in cavern C; (c) infrasound time series near the shelter; (d) Seismogram in cavern B (red arrows indicate the infrasound signal associated with the different surges of the avalanche); (e) magnified infrasound time series; (f) magnified Seismogram near the shelter; $(\mathbf{g})$ magnified Seismogram $(1 \mathrm{~Hz}$ to $3 \mathrm{~Hz})$ near the shelter. Note the similar spindle shape between the seismic $(\mathrm{g})$ and infrasound signals (e). Magnified time series are shown with a different scale of amplitude and all series are plotted on an arbitrary time scale.

size of the avalanche. The spindle shape is also observed in the signals of the seismic sensor placed near the infrasound sensor for all avalanches. In Avalanche 3, the smallest avalanche, the seismic and infrasound signals with a spindle shape have the same length. In Avalanche 2, a clear correlation between seismic and infrasound signals is observed although the seismic part is longer. In Avalanches 1 and 4, however, it was necessary to filter the seismic signal to observe this shape because it was masked by the seismic energy of higher frequency produced by the basal friction of the dense part of the avalanche. Despite the varying amplitudes in the infrasound signal because of the avalanche size ( $0.6 \mathrm{~Pa}$ to $5 \mathrm{~Pa}$ ), the magnitude of the amplitudes of the spindle shape in the seismic signals is always of the same order $\left(10^{-7} \mathrm{~m} \mathrm{~s}^{-1}\right)$.

\section{The source of infrasonic and seismic signals}

Section 3 shows that seismic and infrasound signals generated by snow avalanches have a significantly different tem- poral behaviour during the avalanche descent. For example, Fig. 6c and d (Avalanche 1) highlight clear differences between seismic and infrasound signals recorded at the same place. This is a consequence of the different avalanche flow regimes that interact differently with the environment and hence yield different types of seismic and infrasonic emissions. The main sources of the seismic energy generated by snow avalanches are the basal friction produced by the dense body inside the flow in contact with the ground or snow cover and the changes in the slope of the path (Suriñach et al., 2000; Biescas et al., 2003; Vilajosana et al., 2007b; Schneider et al., 2010). Wet snow avalanches generate especially large and long signals owing to the high-density snow and the relatively slow speed of propagation. In contrast, powder snow avalanches produce comparatively smaller seismic amplitudes because of the low-density snow and high speed of propagation (Biescas et al., 2003).

Despite the large number of studies on avalanche seismic signals, the source of infrasonic emissions of snow avalanches is poorly documented. Since infrasonic emissions are a component of acoustic emission $(f<20 \mathrm{~Hz})$, the appli- 
Table 2. Summary of the maximum amplitudes (MA) of the seismic signals ( $\mathrm{m} \mathrm{s}^{-1}$ ) and the infrasound signal (Pa). Also summarized is the flow duration (FD) of the avalanches flow over the caverns and the total duration based on seismic and infrasonic data.

\begin{tabular}{|c|c|c|c|c|c|}
\hline & & Aval 1 & Aval 2 & Aval 3 & Aval 4 \\
\hline Size & & 5 & 4 & 3 & 4 \\
\hline \multirow[b]{2}{*}{ Cavern A } & FD & $50 \mathrm{~s}$ & & & \\
\hline & MASEIS. & $1 \times 10 \mathrm{~m}^{-3} \mathrm{~ms}^{-1}$ & & & \\
\hline \multirow{2}{*}{ Cavern B } & FD & $50 \mathrm{~s}$ & No flow over cavern & & $25 \mathrm{~s}$ \\
\hline & MA $_{\text {SEIS. }}$ & $2 \times 10 \mathrm{~m}^{-3} \mathrm{~ms}^{-1}$ & $1 \times 10 \mathrm{~m}^{-6} \mathrm{~ms}^{-1}$ & & $5 \times 10 \mathrm{~m}^{-4} \mathrm{~ms}^{-1}$ \\
\hline \multirow[b]{2}{*}{ Cavern $\mathrm{C}$} & FD & & & $20 s$ & $300 \mathrm{~s}$ \\
\hline & MA $A_{\text {SEIS. }}$ & & & $1 \times 10 \mathrm{~m}^{-4} \mathrm{~m} \mathrm{~s}^{-1}$ & $2 \times 10 \mathrm{~m}^{-4} \mathrm{~ms}^{-1}$ \\
\hline \multirow{2}{*}{ Shelter } & MASEIS. $_{\text {. }}$ & $1 \times 10 \mathrm{~m}^{-4} \mathrm{~ms}^{-1}$ & $0.5 \times 10 \mathrm{~m}^{-6} \mathrm{~ms}^{-1}$ & $1 \times 10 \mathrm{~m}^{-6} \mathrm{~ms}^{-1}$ & $5 \times 10 \mathrm{~m}^{-5} \mathrm{~ms}^{-1}$ \\
\hline & $\mathrm{MA}_{I S}$ & $5 \mathrm{~Pa}$ & $1 \mathrm{~Pa}$ & $0.6 \mathrm{~Pa}$ & $2.5 \mathrm{~Pa}$ \\
\hline Total duration & & $500 \mathrm{~s}$ & $230 \mathrm{~s}$ & $80 \mathrm{~s}$ & $495 \mathrm{~s}$ \\
\hline Velocity & & $55 \mathrm{~m} \mathrm{~s}^{-1, \mathrm{a}}$ & & $36 \mathrm{~m} \mathrm{~s}^{-1, b}$ & $20 \mathrm{~m} \mathrm{~s}^{-1, \mathrm{c}}$ \\
\hline
\end{tabular}

The maximum available velocities for each avalanche are also displayed: ${ }^{\mathrm{a}}$ PDR data in cavern $\mathrm{B},{ }^{\mathrm{b}}$ measurement at the pylon, ${ }^{\mathrm{c}}$ average velocity between caverns $\mathrm{B}-\mathrm{C}$ from seismic data.

cation of the general theory of the acoustic emissions to our study is appropriate. Firstov et al. (1992) carried out one of the first studies on acoustic emissions of snow avalanches. These authors suggest that the acoustic signal is generated by the turbulent snow air flow (powder cloud) and that the sound intensity emitted is proportional to the eighth power of the flow velocity, as proposed by Lighthill (1954). In Firstov et al. (1992) the acoustic sound source was considered stationary and was generated by a single eddy. While the approach of Firstov et al. (1992) is consistent with our measurements, which indicate that the acoustic emissions are strongly correlated with the presence of a suspension layer and thus with high avalanche velocities, we believe that the hypothesis of a stationary source is too simplistic. In particular, the avalanche motion will have two effects on the sound emissions in relation to the stationary approach suggested by Firstov et al. (1992) : a change of frequency and a change in the effective source length in the direction of motion. In this regard, a more appropriate approach has been proposed by Ffowcs Williams (1963). To account for a limited source volume and acoustic frequency shift, the Doppler factor $(1-M \times \cos \theta)$ has been introduced; where $\cos \theta$ indicates the direction between source motion and acoustic propagation. Ffowcs Williams (1963) describe the acoustic intensity generated by a moving turbulent source by:

$I \sim \frac{\rho^{2} U^{8}}{\rho_{0} a_{0}^{5}}\left(\frac{D}{|y|}\right)^{2} \frac{1}{|1-M \cos \theta|^{5}}$

where $I$ is the intensity, $\rho$ the fluid density, $\rho_{0}$ the atmospheric density, $a_{0}$ the atmospheric speed of sound, $U$ the flow speed, $D$ the flow dimension, $y$ the distance travelled by the sound wave and $M$ the Mach number $\left(M=U / a_{0}\right)$.

In Sect. 3, we observed that the strong increase in infrasound signal emissions was apparently in correlation with the presence of a fluidised avalanche layer characterized by high speed. In the infrasound time series of Avalanche 1, high amplitudes are observed for the first $120 \mathrm{~s}$ of avalanche motion (Fig. 6c), whereas relatively low amplitudes exist in the seismic signal (Fig. 6d). This behaviour was also observed during Avalanche 4 (Fig. 15c and d).

In order to prove that these high-energy amplitudes in the infrasound signal are attributed to a large turbulent volume of snow with a high flow speed, we calculated the expected acoustic emissions for Avalanche 1 according to Eq. (1) and compared it with the measured values (Fig. 16).

The avalanche front speed gathered from the PDR measurements (Fig. 5) was used for the flow speed $U$. The flow dimension $D$ was fixed, assuming that the avalanche behaves like a compact source with $M \ll 1$, i.e. the sound frequency equals the source frequency as proposed by Crighton (1975). In this case, the flow dimension $D$ can be calculated by $D=U / f$ where frequency $f$ can be deduced from the total spectra of the infrasound measurements (Fig. 7). Using this expression, $D$ varies from $14 \mathrm{~m}$ to $18 \mathrm{~m}$ and is in good agreement with the aerosol height measurements previously obtained for powder snow avalanches at the VDLS test site (Vallet et al., 2004).

High uncertainty exists in the density $\rho$ of the avalanche turbulent layer. According to the literature, the density values may vary from $1 \mathrm{~kg} \mathrm{~m}^{-3}$ to $2 \mathrm{~kg} \mathrm{~m}^{-3}$ for the suspension layer to up to $50 \mathrm{~kg} \mathrm{~m}^{-3}$ for the saltation layer (Nishimura et al., 


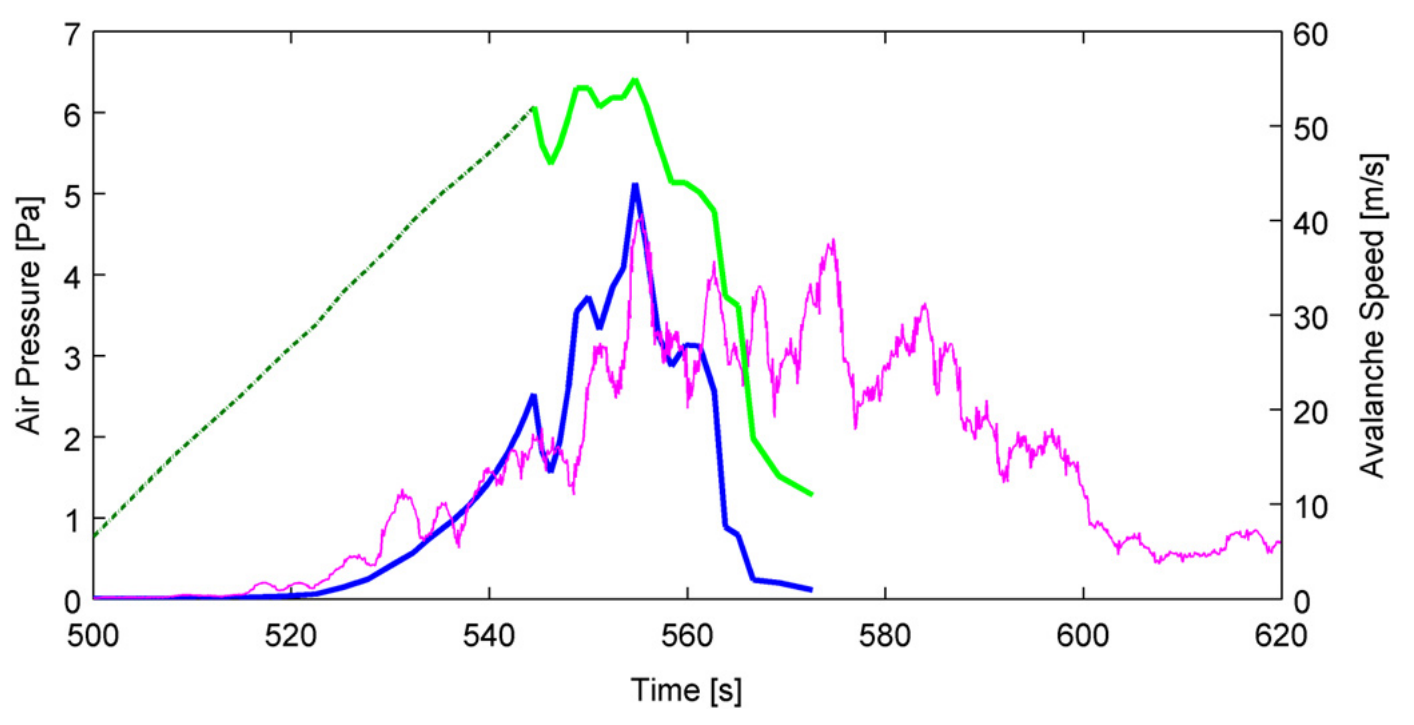

Fig. 16. Air pressure profile in time generated by Avalanche 1 illustrating the infrasound time series (pink line), pressure calculation from Eq. (1) (blue line) and PDR front speed (solid green line) assuming a linear velocity growth in time (dotted green line). The origin of time is the same as in Fig. 6.

1993; Issler, 2003; Turnbull and McElwaine, 2007). The best fit in Fig. 16 between measured and calculated values was obtained with a density $\rho$ of $2.5 \mathrm{~kg} \mathrm{~m}^{-3}$. This is consistent with the calculated flow dimension $D$, which corresponds to the typical height of avalanche suspension layers. Finally, we assumed a value of $\theta=10^{\circ}$ to describe the direction between source motion and acoustic propagation. We used equation $I=p^{2} / \rho_{0} c_{0}$ (e.g. Hirschberg and Rienstra, 2004) for plane waves to convert sound intensity $I$ to pressure $p$.

Figure 16 shows the calculated pressure values for Avalanche 1 (blue line) against the envelope of our infrasound measurements (pink line). In the time interval [ $540 \mathrm{~s}$ to $560 \mathrm{~s}$ ], the calculated and measured values are in agreement. The calculated signal decreases in amplitude after $560 \mathrm{~s}$ due to the rapid fall in the avalanche front speed. The monitored values (pink line) however, remain high $(5 \mathrm{~Pa})$. This apparent discrepancy can be explained by recalling that values calculated from Eq. (1) (blue line) represent only the avalanche front and do not take into account the possibility that the suspension layer spreads over a large area of the avalanche path. In fact, while the avalanche front suddenly decelerated at the start of the runout zone, radar measurement reveals that there were still high velocities for about $50 \mathrm{~s}$ in the upper avalanche path (see Sect. 3.1.1).

The relatively small seismic amplitudes in the sensor near the shelter for Avalanche 1 [500 s to $600 \mathrm{~s}$ ] (Fig. 6d) are also in line with the existence of a low-density flow regime in the initial phase of this avalanche. According to earlier studies, seismic observations of powder snow avalanches show that the generated ground vibrations are very weak (Nishimura et al., 1993; Suriñach et al., 2001). In particular, seismic waves are relatively small during the initial acceleration of the avalanche because a certain amount of snow mass is necessary to generate sufficient seismic energy for detection by seismometers (Suriñach et al., 2000). A similar behaviour of infrasound and seismic amplitudes can be observed for Avalanche 4 (Fig. 15c and d). The amplitudes in the infrasound rapidly decrease before Avalanche 4 reaches Cavern B. At the same time the amplitudes in the seismic signal in the shelter increase. The analysis of the seismic signals in the caverns indicates that Avalanche 4 had still an average speed of $20 \mathrm{~m} \mathrm{~s}^{-1}$ between Cavern $\mathrm{B}$ and $\mathrm{C}$, which rapidly decreased to $5 \mathrm{~m} \mathrm{~s}^{-1}$ at the pylon. Using the same reasoning as in the case of Avalanche 1, it may be concluded that the high amplitudes in the infrasonic data are related to the presence of a suspension layer in the upper avalanche path. The smaller amplitudes in the infrasound of Avalanche 2 with respect to those of Avalanche 1 can also be explained if we assume that most of the infrasound signals come from the suspension part. As for Avalanche 2 (Pra Ruoa), the potential erosion area was smaller than that of Avalanche 1 (CrêtaBesse). Consequently, the erosion of snow along the path of Avalanche 2 was limited, and as a result, the development of the suspension layer (Sovilla et al., 2006). Pressure changes in the seismic sensor or infrasound-seismic coupling as observed in other sources (e.g., Hayward and Pankow, 2008; Negraru, 2010) may account for the spindle shape of the seismic data (filtered or not) at the start of the avalanche.

\section{Conclusions}

The infrasound and seismic signals generated by four different snow avalanches released naturally at the Vallée de La Sionne test site were analysed. We showed that infrasound 
and seismic signals are correlated with each other and that the combination of both sensors is a valuable tool for detecting snow avalanches. Both sensors can detect avalanches despite being sensitive to different avalanche regimes. Infrasound sensors are more sensitive to the aerosol fluctuations (powder part), whereas seismic sensors are more sensitive to the vibrations generated by the dense flow. Thus, while infrasound sensors readily perceive avalanches in the early stages of an event, provided that the suspension part is present, seismic sensors detect avalanches as soon as they have enough mass to generate signals that can be discriminated from the ambient noise.

In addition, the main findings of this study may be summarized as follows:

1. The combination of infrasound and seismic sensors used allowed us to estimate the total avalanche duration with high reliability and accuracy. The infrasound sensor proved more suitable for detecting avalanche initiation and the seismic sensors more suitable for estimating the end of the avalanche motion. The avalanche stopping phase was only detected by the seismic sensors.

2. High amplitudes in the infrasound measurement were related to the suspension layer in the upper avalanche path. For one of the measured avalanches, we were able to reproduce the measured infrasound signal, assuming that the suspension layer acted as a moving turbulent sound source and that the infrasonic emission intensity was proportional to flow speed and to the height of the suspension layer.

3. The amplitudes of the infrasound and seismic signals were roughly correlated with the size of the suspension and dense layer, respectively.

4. The combination of infrasound and seismic sensors not only detected the avalanches but also differentiated between the different flow regimes.

Acknowledgements. The authors would like to thank L. Rammer (BFW) for providing the radar data and for fruitful discussions. This study was supported by the following projects: BOKU Doc Grants 2008 and the projects CGL2006-06596/BTE, CSD200600041 and CGL2010-18609 (R\&D Plan MICINN and FEDER Founds, Spain). I. V. is supported by a Torres Quevedo grant from the Spanish Ministerio de Ciencia e Innovación 2008-03-08109. Velocity and flow depth measurements were partly funded by the Swiss National Foundation under grant 20602-113069/1.

Edited by: J. M. Vilaplana

Reviewed by: two anonymous referees

\section{References}

Adam, V., Chritin, V., Rossi, M., and Bolognesi, R.: Acoustic detection system for operational avalanche forecasting, in: International Snow Science Workshop, Banff, Alberta, 149-153, 1997.

Barbolini, M. and Issler, D.: Avalanche Test Sites and Research Equipment in Europe: An Updated Overview, Tech. rep., FinalReport Deliverable D8, SATSIE Avalanche Studies and Model Validation in Europe, 2006.

Bedard, A.: Detection of avalanches using atmospheric infrasound, in: Proceedings of the Western Snow Conference, edited by: Shafer, B., Western Snow Conference, Colorado State University, 52-58, 1989.

Bessason, B., Eiríksson, G., Thórorinsson, Ó., Thórorinsson, A., and Einarsson, S.: Automatic detection of avalanches and debris flows by seismic methods, J. Glaciol., 53, 461-472, 2007.

Biescas, B.: Aplicación de la sismología al estudio y detección de aludes de nieve, Ph.D. thesis, Universitat de Barcelona, Grup d'Allaus UB, Departament de Geodinàmica i Geofísica, 2003.

Biescas, B., Dufour, F., Furdada, G., Khazaradze, G., and Suriñach, E.: Frequency content evolution of snow avalanche seismic signals, Surv. Geophys., 24, 447-464, 2003.

Comey, R. and Mendenhall, T.: Recent Studies Using Infrasound Sensors to Remotely Monitor Avalanche Activity, in: International Snow Science Workshop, Jackson Hole, Wyoming, 640646, 2004.

Crighton, D.: Basic Principles of Aerodynamic Noise Generation, Prog. Aerosp. Sci., 16, 31-96, 1975.

Ffowcs Williams, J.: The noise from Turbulence Convected at High Speed, Philos. T. R. Soc. A, 255, 469-503, 1963.

Firstov, P., Sukhanov, L., Pergement, V., and Rodionovskiy, M.: Acoustic and seismic signal from snow avalanches, Transactions (Doklady) of the U.S.S.R. Academy of Sciences: Earth Science Sections, 312, 67-71, 1992.

Gauer, P., Issler, D., Lied, K., Kristensen, K., and Sandersen, F.: On snow avalanches flow regimes: Inferences from observations and measurements, in: International Snow Science Workshop, Whistler, 717-723, 2008.

Hayward, C. and Pankow, K.: Obervations of infrasound to seismic coupling at Earthscope stations using co located infrasound microphones, Eos Trans. AGU, S33B-1945, 89, 2008.

Hirschberg, A. and Rienstra, S.: An introduction to aeroacoustics, Tech. rep., Eindhoven University of Technology, Dept. of App. Physics and Dept. of Mathematics and Comp. Science, 2004.

Issler, D.: Experimental information on the dynamics of dry-snow avalanches, Lecture Notes in Applied and Computational Mechanics, pringer, Berlin, Germany, vol. 11, chap. I, 109-150, 2003.

Kern, M., Bartelt, P., Sovilla, B., and Buser, O.: Measured shear rates in large dry and wet snow avalanches., J. Glaciol., 55, 327338, 2009.

Kogelnig, A., Hübl, J., Suriñach, E., Vilajosana, I., and McArdell, B.: Infrasound produced by debris flow:propagation and frequency content evolution, Nat. Hazards, doi:10.1007/s11069011-9741-8, 2011.

Leprettre, B., Martin, N., Glangeaud, F., and Navarre, J.: ThreeComponent Signal Recognition Using Time, Time-Frequency, and Polarization Information-Application to Seismic Detection of Avalanches, IEEE T. Signal Proces., 46, 83-102, 1998.

Lighthill, M.: On sound generated aerodynamically II, Turbulence 
as a source of sound, P. R. Soc. London, 222, 1-32, 1954.

McClung, D. and Schaerer, P.: Snow Avalanche Size Classification, in: Proceedings of Avalanche Workshop, edited by Comittee, C. A., vol. Technical Memorandum 133, Associate Committee on Geotechnical Research, Ottawa: National Research Council of Canada, 12-27, 1980.

McClung, D. and Schaerer, P.: The Avalanche Handbook, The Mountaineers Books, 2006.

Negraru, P. T.: Application of Seismo-Acoustic Signals to the Study of Local Site Effects, Acta Geophys., 58(6), 1021-1039, doi:10.2478/s11600-010-0025-6, 2010.

Nishimura, K., Maeno, N., Kawada, K., and Izumi, K.: Structures of snow cloud in dry-snow avalanches, Ann. Glaciol., 18, 173178, 1993.

Rammer, L., Kern, M., Gruber, U., and Tiefenbacher, F.: Comparison of avalanche-velocity measurements by means of pulsed Doppler radar, continous wave radar and optical methods, Cold Reg. Sci. Technol., 50, 35-54, 2007.

Sabot, F., Naaim, M., Granada, F., Suriñach, E., Planet, P., and Furdada, G.: Study of avalanche dynamics by seismic methods, image processing techniques and numerical models, Ann. Glaciol., 26, 319-323, 1998.

Saint-Lawrence, Y. and Williams, T.: Seismic signals associated with avalanches, J. Glaciol., 17, 521-526, 1976.

Salway, A.: A Seismic and Pressure Transducer System for Monitoring Velocities and Impact Pressure of Snow Avalanches, Arctic Alpine Res., 10, 769-774, 1978.

Schneider, D., Bartelt, P., Caplan-Auerbach, J., Christen, M., Huggel, C., and McArdell, B.: Insights into rock-ice avalanche dynamics by combined analysis of seismic recordings and a numerical avalanche model, J. Geophys. Res., 115, F04026, doi:10.1029/2010JF001734, 2010.

Scott, E., Hayward, C., Kubichek, R., Hamann, J., and Pierre, J.: Results of Recent Infrasound Avalanche Monitoring Studies, in: International Snow Science Workshop, Jackson Hole, Wyoming, 696-704, 2004.

Scott, E., Hayward, C., Kubichek, R., Hamann, J., Comey, R., Pierre, J., and Mendenhall, T.: Single and multiple sensor identification of avalanche-generated infrasound, Cold Reg. Sci. Technol., 47, 159-170, 2007.

Sovilla, B., Burlando, P., and Bartelt, P.: Field experiments and numerical modeling of mass entrainment in snow avalanches, $\mathrm{J}$. Geophys. Res., 111, F03007, doi:10.1029/2005JF000391, 2006.

Sovilla, B., Schaer, M., Kern, M., and Bartelt, P.: Impact pressures and flow regimes in dense snow avalanches observed at the Vallée de la Sione test site, J. Geophys. Res., 113, 1-14, doi:10.1029/2006JF000688, 2008a.
Sovilla, B., Schaer, M., and Rammer, L.: Measurements and analysis of full-scale avalanche impact pressure at the Vallée de la Sionne test site, Cold Reg. Sci. Technol., 51, 122-137, 2008 b.

Sovilla, B., Kern, M., and Schaer, M.: Slow drag in wet snow avalanche flow, J. Glaciol., 56, 587-592, 2010a.

Sovilla, B., McElwaine, J., Schaer, M., and Vallet, J.: Variation of deposition depth with slope angle in snow avalanches: Measurements from Vallée de la Sionne, J. Geophys. Res., 115, F02016, doi:10.1029/2009JF001390, 2010b.

Stein, S. and Wylesession, M.: An Introduction to seismology, earthquakes and earth structure, Blackwell Publishing, 2003.

Suriñach, E.: Spanish avalanche research: Experimental sites and seismic measurements, in: Snow and Avalanche Test Sites, edited by: Naaim, M. and Naaim-Bouvet, F., Cemagref, 71-183, 2004.

Suriñach, E., Sabot, F., Furdada, G., and Vilaplana, J. M.: Study of Seismic Signals of Artificially Released Snow Avalanches for Monitoring Purposes, Phys. Chem. Earth, 25, 721-727, 2000.

Suriñach, E., Furdada, G., Sabot, F., Biescas, B., and Vilaplana, J. M.: On the characterization of seismic signals generated by snow avalanches for monitoring purposes, Ann. Glaciol., 32, 268-274, 2001.

Suriñach, E., Vilajosana, I., Khazaradze, G., Biescas, B., Furdada, G., and Vilaplana, J. M.: Seismic detection and characterization of landslides and other mass movements, Nat. Hazards Earth Syst. Sci., 5, 791-798, doi:10.5194/nhess-5-791-2005, 2005.

Suriñach, E., Kogelnig, A., Vilajosana, I., Hübl, J., Hiller, M., and Dufour, F.: Incorporación de la señal de infrasonido a la detección y estudio de aludes de nieve y flujos torrenciales, in: VII Simposio Nacional sobre Taludes y Laderas Inestables, edited by: Alonso, E., Corominas, J., and Hürlimann, M., Barcelona, Spain, 2009.

Turnbull, B. and McElwaine, J.: A comparison of powder-snow avalanches at Vallée de la Sionne, Switzerland, with plume theories, J. Glaciol., 53, 30-40, 2007.

Vallet, J., Turnbull, B., Joly, S., and F., D.: Obervations on powder snow avalanches using videogrammetry, Cold Reg. Sci. Technol., 39, 153-159, 2004.

Vilajosana, I., Khazaradze, G., Suriñach, E., Lied, E., and Kristensen, K.: Snow avalanche speed determination using seismic methods, Cold Reg. Sci. Technol., 49, 2-10, 2007a.

Vilajosana, I., Suriñach, E., Khazaradze, G., and Gauer, P.: Snow avalanche energy estimation from seismic signal analysis, Cold Reg. Sci. Technol., 50, 72-85, 2007 b. 